\title{
GRAPHENE/(h-BN $)_{n} /$ X-DOPED GRAPHENE AS ANODE MATERIAL IN LITHIUM ION BATTERIES (X = Li, Be, B AND N)
}

\author{
Majid Monajjem \\ Department of Chemistry, Science and Research Branch, Islamic Azad University, Tehran, Iran \\ m_monajjemi@srbiau.ac.ir
}

In this study boron nitride $(\mathrm{BN})$ sheet has been localized inside two $\mathrm{X}$-graphene electrodes as an option to enhance the electrochemical ratio. Additionally, we have found the structure of $\mathrm{X}-\mathrm{G} /(\mathrm{h}-\mathrm{BN})_{n} / \mathrm{X}-$ $\mathrm{G}(n=2-5)$ can improve the capacity and electrical transport in C-BN sheet-based lithium ion batteries (LIBs). Therefore, the modification of $\mathrm{BN}$ sheets and design of $\mathrm{X}-\mathrm{G} /(\mathrm{h}-\mathrm{BN})_{n} / \mathrm{X}-\mathrm{G}$ structure provide strategies for improving the performance of $\mathrm{BN}$ graphene based anodes. $\mathrm{X}-\mathrm{G} /(\mathrm{h}-\mathrm{BN})_{n} / \mathrm{X}-\mathrm{G}$ could also be assembled into free- standing electrodes without any binder or current collector, which will lead to increased specific energy density for the overall battery design. In this work the measured reversible lithium ion capacities of $\mathrm{X}-\mathrm{G} / /(\mathrm{h}-\mathrm{BN}) / / \mathrm{X}-\mathrm{G}(\mathrm{X}=\mathrm{Be}, \mathrm{B}, \mathrm{N})$ based anodes are considerably improved compared to the conventional graphite-based anodes

Keyword: graphene; doping; anode lithium; ion battery; LIBs; nano capacitor

\section{ГРАФЕН ДОПИНГУВАН СО ГРАФЕН/(h-ВN) ${ }_{n} / \mathrm{X} \mathrm{КАКО} \mathrm{АНОДЕН} \mathrm{МАТЕРИЈАЛ}$ ВО БАТЕРИИ СО ЛИТИУМОВИ ЈОНИ (X = Li, Be, В И N)}

Во ова истражување плоча од бор нитрид (BN) беше вметната во внатрешноста на две Xграфенски електроди како можност да се подобри електрохемискиот однос. Дополнително утврдивме дека структурата на $\mathrm{X}-\mathrm{G} /(\mathrm{h}-\mathrm{BN})_{n} / \mathrm{X}-\mathrm{G}(n=2-5)$ може да го подобри капацитетот и електричниот транспорт на C-BN-плочите во батериите базирани на литиумови јони (LIBs). Произлегува дека модификацијата на плочите од BN и градбата на структурата на X-G/(h-BN)n $/ \mathrm{X}$ $\mathrm{G}$ отвораат стратегии за подобрување на перформансите на графенските аноди со BN. X-G/(h$\mathrm{BN})_{\mathrm{n}} / \mathrm{X}-\mathrm{G}$ можат да се изградат како самостојни електроди без сврзувачко средство или колектор на струјата што ќе доведе до зголемена специфична густина на севкупната градба на батеријата. Во овој труд измерените реверзибилни капацитети на анодите $\mathrm{X}-\mathrm{G} / /(\mathrm{h}-\mathrm{BN}) / / \mathrm{X}-\mathrm{G}(\mathrm{X}=\mathrm{Be}, \mathrm{B}, \mathrm{N})$ се значително подобри во однос на конвенционалните аноди базирани на графен.

Клучни зборови: графен; допингување; аноден литиум; јонски батерии; LIBs; нано кондензатори

\section{INTRODUCTION}

Doped nano-graphene compounds have displayed great potentials as anode material for lithium ion batteries (LIBs) due to their unique structural, electrical and mechanical properties. The measured reversibility of LIBs containing graphene//(h-BN $)_{\mathrm{n}} / /$ graphene-based anodes is considerably improved compared to those with conventional 'graphite-based-anodes'. Boron-and ni- trogen-doped graphene compounds have displayed great yields as anode materials for lithium ion batteries (LIBs) due to their unique structural, mechanical, and electrical properties.

The structures of graphite and hexagonal nano-boron nitride ( $\mathrm{h}-\mathrm{BN}$ ), parent materials for carbon nanotubes and boron nitride nanotubes, are quite similar. They are both materials composed of layers of hexagonal lattices; graphite has carbon atoms at all lattice points, while h-BN is composed 
of alternating atoms of boron and nitrogen. Inplane lattice constants are $2.46 \AA$ for graphite [1] and $2.50 \AA$ for h-BN [2]. In contrast to graphite, layered of h-BN is transparent and is an insulator. In h-BN, layers are arranged so that boron atoms in one layer are located directly on top of nitrogen atoms in neighboring layers, and vice versa, and the hexagons lie on top of each other. In graphite, the stacking is slightly different; hexagons are offset and do not lie on top of each other. Interlayer distances are similar: $3.35 \AA$ for graphite [1] and $3.33 \AA$ for h-BN, Figure1. [2].

With the discovery in 1991 of highly reversible, Li-intercalation carbonaceous materials and low-voltage batteries, Sony realized the commercialization of $\mathrm{xC}_{6} / \mathrm{Li}_{1-x} \mathrm{CoO}_{2}$ cells [3-7]. Lithium-ion batteries, or LIBs, are significant energy storage devices based on electrochemical energies, widely used in a range of storage systems. The favorable electrochemical efficiencies of LIBs regarding energies, cell design and power densities, as well as progress in manufacturing have made LIBs greatly successful for electronic devices.

The electronic properties of graphite and h$\mathrm{BN}$ are radically different from each other. Recent theoretical calculations have demonstrated [3] the band structures of a single layer of graphite and h$\mathrm{BN}$, while for a single layer of graphite, a graphene, two bands cross each other at the Fermi energy. Thus, a graphene is a semimetal. Unlike a graphene, in a single layer of $\mathrm{h}-\mathrm{BN}$, equivalent bands do not cross each other and a $4.5 \mathrm{eV}$ band gap forms. Experimentally, bulk h-BN has been measured to have a band gap of $5.8 \mathrm{eV}$ [4].

Crystallographically, h-BN is classified into four polymorphic forms: hexagonal $\mathrm{BN}$ (h-BN) (Fig 1(a); rhombohedral BN (r-BN); cubic BN (c$\mathrm{BN})$; and wurtzite $\mathrm{BN}(\mathrm{h}-\mathrm{BN})$. BN does not occur in nature. (a)

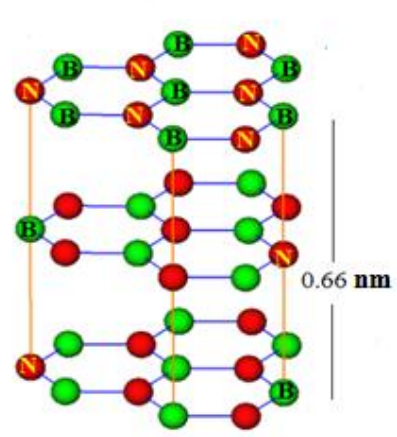

(b)

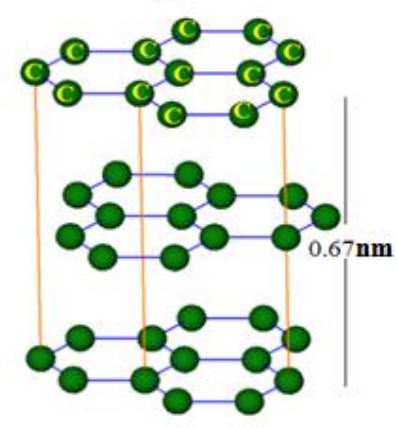

Fig. 1. Crystal structures of (a) graphite; (b) hexagonal boron nitride
In 1842, Balmain [5] obtained BN as a reaction product between molten boric oxide and potassium cyanide at atmospheric pressure. Thereafter, many methods for its synthesis have reported $[3,4](1) \mathrm{h}-\mathrm{BN}$ and $\mathrm{r}-\mathrm{BN}$ formed under ambient pressure (2), c-BN synthesized from h-BN under high pressure at high temperature (3), and w-BN prepared from h-BN under high pressure at room temperature [6].

LIBs basically consist of a positive electrode as cathode, a negative electrode as anode and a conducting electrolyte, where electrical energy is stored in those electrodes in the form of $\mathrm{Li}$ intercalation compounds. Electrodes, electrolyte, and separator are the main components of a LIB, while the anode plays an essential role for increasing the efficiency of these devices.

During charging of LIBs, lithium ions released from the cathode move through the electrolyte and are inserted into the anode. Upon discharging, lithium ions are extracted from the anode and move back to the cathode. Although the electrolyte establishes high ionic conductivity between the two electrodes, the electrolytes are not responsible for the conduction of free electrons and so the electrons complete the half reaction by moving through an external wire. Graphite is currently the most common material used for the anodes of commercial batteries because of its capability for reversible lithium intercalation in the layered crystals, and represents the maximum theoretical lithium storage capacity around "372 mAh/g" [8].

Numerous experiments have been performed to confirm the use of graphene nano-sheets and nano-ribbons to enhance lithium storage capacity and to improve cyclic recharging performance [911]. Furthermore, semi-empirical molecular orbital calculations have been used to investigate lithium ion storage states between two graphene sheets [12], as well as some heteroatom-substituted carbon materials [13]. There have been a number of reviews on anode materials [12-17] and many of them focus on both carbon and inorganic materials.

Discharging and charging of LIBs using graphitized carbon is well established and has been documented [18-21]. It has also been shown how repulsive forces in a mixed stage can result in a pure stage during intercalation [19]. Although attempts have been made to find suitable replacements, currently only carbonaceous materials are used in commercial anodes [22]. The Properties of carbonaceous materials largely depend on the starting materials, such as the carbon precursor, and on the heat treatment [23]. 
The present work has investigated finding a suitable replacement for the carbonaceous materials and has illustrated a novel mechanism of the capacitor-anode cell interaction (Figs. 1-3). As the efficiency of an LIB, including cycle life, power density and energy density are strongly influenced by anode materials (positive side), certain characteristics to maximize battery performance have been considered in our model. These items include critical changes in the crystal structure of the anode material and fast diffusivity of lithium ions [15-25].

In this study, charging and discharging of LIBs is investigated using $\mathrm{h}-\mathrm{BN}$, with the positive electrode reaction being:

$$
\mathrm{LiCoO}_{2} \rightleftarrows \mathrm{Li}_{1-x} \mathrm{CoO}_{2}+x \mathrm{Li}++x e^{-}
$$

The negative electrode reaction as:

$$
x \mathrm{~B}_{3} \mathrm{~N}_{3}+x \mathrm{Li}^{+}+x e^{-} \rightleftarrows x \mathrm{LiB}_{3} \mathrm{~N}_{3}
$$

and the whole reaction is:

$$
\mathrm{LiCoO}_{2}+x \mathrm{~B}_{3} \mathrm{~N}_{3} \rightleftarrows \mathrm{Li}_{1-x} \mathrm{CoO}_{2}+x \mathrm{LiB}_{3} \mathrm{~N}_{3}
$$

It has been suggested that lithium atoms are stored via two mechanisms: intercalation and alloying [24].

Recently many works have investigated the intercalation and diffusion of $\mathrm{Li}$ at different sites on graphite and many studies have been performed in order to explain the mechanism by which lithium ions are stored in graphite, including theoretical works [13-24]. Yang et al. [25] proposed a surface mechanism by which the naked surface of carbon nanoparticles are able to store lithium species, by investigation of the electrochemical intercalation of lithium into graphite. They found that both sides are susceptible to lithium intercalations, and achieved a high Li density.

Graphite is known as a zero band gap semimetal due to its unique conduction behavior under the influence of electrical fields [26, 27]. Interlayer forces are small (Van der Waals forces), and the distance between graphene layers is large $(3.35 \AA)$ [21] allowing $\mathrm{Li}$ ions to diffuse easily between graphene sheets. Electrical conductivity of the Ligraphene increases with increasing intercalation levels, due to the electron donor nature of $\mathrm{Li}$. This is the opposite of ionic conduction, in which diffusivity decreases due to the insertion of $\mathrm{Li}$ ions. In the case of amorphous carbon, as the disorder increases, electrical conductivity significantly decreases.
Amorphous carbon is known to be composed of small carbon sheets [28], and is of interest due to its much higher capacity than graphitized carbon. The Li ion diffusivity in amorphous carbon is generally much greater than that in graphitized carbon and also the diffusion process can vary widely from one type of carbon to another [29-31]. Surface modification of carbon by mild oxidation, deposition of metals, and coating with polymers or other types of carbon has been shown to increase cell performance [32]. Boron-doped graphite has also been researched as an option to enhance electrochemical ratio. Amorphous carbon is known to be composed of small carbon sheets [28]. In our previous works the electronic structures of graphite and h-BN with graphite have been researched [3339]. While first-principles calculations are not applicable for analyzing the electronic structure of amorphous carbon, various models considering hybridization of $\mathrm{sp}^{3}$ and $\mathrm{sp}^{2}$ atomic orbitals have been developed to predict electrical conductivities in this material [40-44].

Classically, a short circuit is defined as a circuit element across which the voltage is zero, regardless of the current flowing through it [45]. Consequences include excessive electric current flow, causing circuit damage, overheating, fire or explosion. From a safety point of view, internal or external short circuits of Li-ion batteries [46] are very important because they can cause a sudden increase in heat generation, called thermal runaway [47]. Recently many researchers have focused on graphite-based anodes for LIBs with varying success, depending on the treatments employed. In this study we provide new approaches of graphene/ (h-BN) ${ }_{n} /$ X-doped graphene in LIB anode applications with respect to structural and properties of boron and nitrogen doped atoms. As one type of porous carbon material, graphene/(h-BN) $/ \mathrm{X}$ doped graphene have been extensively investigated as anode materials for Li-ion batteries due to their mesoporous character, high chemical stability, low resistance, high mechanical strength, and highly activated surfaces [48-51].

In comparison to the theoretical maximum capacity of graphite at $372 \mathrm{mAh} / \mathrm{g}(\mathrm{LiC})$, the electrochemical intercalation of lithium with graphene/(h-BN) $)_{n} / \mathrm{X}$-doped graphene has been studied with higher capacities in recent years [5259]. However, the nature of carbon materials restricts their capacity; some scientists fabricate particular microstructures to improve the electrochemical properties of graphene/(h-BN $)_{n} / \mathrm{X}$-doped graphene [60, 61]. 
It is notable that the Fisher group fabricated a tube-in-tube structure with a $\mathrm{Li}^{+}$intercalation capacity two times higher than that of the templatesynthesized CNTs, as the inner tubules provided more electrochemically active sites for intercalation of $\mathrm{Li}$ ions [62].

The intercalation of lithium into graphite involves one lithium atom per six carbon atoms, i.e. $\mathrm{LiC}_{6}$, leading to a limited specific capacity of 372 $\mathrm{mAh} / \mathrm{g}$ and an observed capacity of 280-330 $\mathrm{mAh} / \mathrm{g}$, depending on the type of graphite used [63-65]. Allotropes of graphite have been reported to show much improved lithium capacity compared to graphite, due to their unique structures and properties [65-71].

Obviously, the most direct way to improve the capacity of graphene/(h-BN $)_{n} / \mathrm{X}$-doped graphene anodes is to fabricate composite electrodes of graphene/(h-BN $)_{n} / \mathrm{X}$-doped graphene with other materials. In such hybrid systems, the graphene/(h-BN $)_{n} / \mathrm{X}$-doped graphene functions as an effective buffer, confining the mechanical stress induced by volume changes in charging and discharging reactions, while the other nanomaterials provide a high capacity. The flexibility, porosity, and conductivity of graphene/(h-BN) $/ \mathrm{X}$-doped graphene gave scientists an insight into the fabrication of 'paper electrodes'. Graphite networks and aligned graphite/conducting polymers were then exploited for paper electrodes, and the capacity of the latter was 50\% higher than that of an SWNT paper electrode [70, 71].

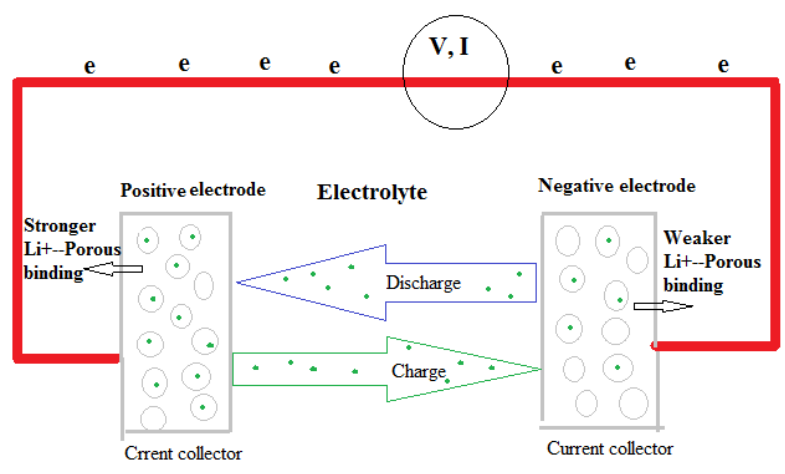

Scheme1. Illustration of an LIB. The spheres are the active particles of the two porous electrodes in which $\mathrm{Li}^{+}$ions (the green dots) can be stored. The voids between particles and between the electrodes are filled with an electrolyte in which $\mathrm{Li}^{+}$diffuse and migrate thermodynamically. Electrons, on the other hand, have to move through the external circuit.

Energies and power capabilities of lithium ion batteries depend critically on the rate at which $\mathrm{Li}^{+}$ions and electrons can migrate from the electrolyte and electrode support. Basically, in all
LIBs, the two electrodes are made of a porous active particle skeleton filled with electrolyte, while there are different charge-transport mechanisms. The transport of charges and species between the electrolyte and the active particles were described with the 'Butler-Volmer' reaction model [56]. In 'non-equilibrium thermodynamics' the binding to the anode material matrix (M) should be weaker than that on the cathode (negative) side, which means the $\mathrm{Li}^{+}$ions at the anode are naturally discharged, and move to cathode (Scheme 1).

Although the materials used as the two electrodes for $\mathrm{Li}^{+}$storage should have strength of binding with $\mathrm{Li}^{+}$within a certain range, binding to anode (positive side) material matrix ' $M$ ' should be weaker than on the negative electrode or cathode. On the other hand, this binding energy $E_{L i-M}$ should be greater than cohesive the energy $E_{L i}$ of lithium, in order to prevent the hazardous phase separation of Li dendrites.

Basically, the charge of an inserted $\mathrm{Li}^{+}$ion is instantaneously shielded by local rearrangements of electronic charge and the transport of an electron into the active particle over the current collectors and circuits in the electrolyte; the transport of positive and negative ions and charge species are strongly coupled. The fluxes and charges of both species are caused by gradients in the electrical potential as well as by gradients in the chemical potential, and those relations are well known for dilute electrolytes. Although for a dilute electrolyte it is possible to use the stronger binding of $\mathrm{Li}$ with the anode rather than with the cathode, in lithium ion batteries we have to deal with highly concentrated electrolyte. Really, local charge neutrality is preserved in a concentrated electrolyte except for the diffuse parts of the multilayer around the active particle [72-76].

In summary, graphene and h-BN sheets, as classical materials with a mature study history will play a significant role in the battery market in the near future, but how to combine hybrid materials to obtain safe, stable, and high-capacity electrodes has always been the radical problem that many researchers are trying to solve [77-80].

\section{THEORETICAL BACKGROUNDS}

\subsection{Diffusion in condensed materials}

Diffusion properties within a Li-ion cell determine some of the key performance metrics of the cell, including the charge and discharge rate, practical capacity and cycling stability. The governing equation describing the diffusion process is known as Fick's law: 
$j_{i}=-D_{i} \nabla C_{i}(\mathbf{1}) \quad$ and $\quad \frac{\sigma C_{i}}{\sigma t}=\nabla \cdot\left(D \nabla C_{i}\right)$

where $j_{i}$ is ionic flux in mol cm $\mathrm{cm}^{-2} \mathrm{~s}^{-1}, D_{i}$ is diffusivity of solute $(i=1,2)$ in $\mathrm{cm}^{2} \mathrm{~s}^{-1}$ and $C_{i}$ is concentration of species I in $\mathrm{mol} \mathrm{cm}^{-3}$ [81].

The proportionality factor $D$ is the diffusivity or diffusion coefficient $[81,82]$ :

$$
D_{i}=\frac{K_{B} T}{6 \pi \mu R_{0}}
$$

Li-ion cells included, all key phenomena involve conducting charged particles; in a primary cell from cathode to anode, or vice versa in a secondary cell, from anode to cathode.

A typical commercial lithium-ion battery consists of several interconnected electrochemical cells, where each cell is composed of a graphite anode (such as meso-carbon microbeads), a cathode formed by lithium metal oxide (such as $\mathrm{LiCoO}_{2}$ ) and electrolyte (such as $\mathrm{LiPF}_{6}$ dissolved in ethylene carbonate/dimethyl carbonate mixture) embedded in separator felt.

In condensed materials, both liquids and solids, diffusion is governed by random jumps of atoms or ions, leading to position exchange with their neighbors. The kinetics of this process is temperature dependent and follows an Arrheniustype relationship [83]:

$$
\text { rate } \approx \exp \left(-\frac{\Delta G}{k_{B} T}\right)
$$

In liquids, the temperature dependence of diffusion is much less than in solids. Note that no successful first-principles calculation has been made, due to insufficient understanding of the liquid structure [81]. Thus, a simple expression derived from Stokes' law is frequently used as an alternative to a diffusivity expression in liquids (Eq. 3) [81].

Although the $\mathrm{Li}^{+}$ion is one of the smallest ions, it is still big when compared to electrons; the radius of $\mathrm{ai}^{+}$ion is ten orders of magnitude larger than that of an electron. Also the motion of $\mathrm{Li}^{+}$ ions is strongly impeded by the potential created by the presence of neighboring ions as discussed below.

Thus diffusion can be the rate-determining process compared to electronic conduction in an electrochemical reaction. The Van der Waals interaction, expressed as the Lennard-Jones potential, is relatively weak despite showing a longer interaction range. In the case of a graphite anode, $\mathrm{a} \mathrm{Li}^{+}$ ion can easily diffuse parallel rather than perpen- dicular to the graphene layers during intercalation. Thus in order to understand the diffusion of the $\mathrm{Li}^{+}$ ion it is important to consider crystal structure as well as the surrounding potential.

\subsection{Anode materials}

In the case of the anode, Li metal is found to be the most electropositive ( $-3.04 \mathrm{~V}$ versus standard hydrogen electrode) with large reversible capacity $\left(\approx 4000 \mathrm{~A} \mathrm{~h} \mathrm{~kg}^{-1}\right)$. However, due to safety considerations (explosion hazards as a result of dendrite growth during cycling), metallic Li has been substituted by various carbonaceous materials [89].

Carbon-lithium anodes have much lower gravimetric and volumetric energy densities than pure lithium which has led to the development of interstitial-free $3 \mathrm{~d}$ transition metal oxides $(\mathrm{MnOm}$, $\mathrm{M}=\mathrm{Fe}, \mathrm{Co}, \mathrm{Ni}, \mathrm{Mn}, \mathrm{Cu})$. These materials are able to incorporate more than one $\mathrm{Li}^{+}$per metal through conversion (displacement) reactions giving higher capacities $\left(\approx 800 \mathrm{~A} \mathrm{~h} \mathrm{~kg}^{-1}\right)$ in comparison to carbon anodes [90-93].

Conduction in graphite anodes is complex due to continuous phase transformations and the formation of the SEI layer. Phase transformations are reflected in the open-circuit voltage (OCV) curve as distinct plateaus [94]. Also conduction is strongly dependent upon the degree of crystallinity. Non-graphitic carbonaceous materials do not undergo phase transformations and therefore do not show distinctive stages in the OCV curve [94, 95]. The SEI layer displays much lower ionic and electronic conductivity than the bulk electrode. To elucidate the mechanisms related to the properties and performance of Li-ion batteries, precise investigation of the electronic state and the diffusion process in the carbon and the SEI layer is still required.

The diffusivity of Li-ions in graphite is complicated by the constant phase change in the Li-graphite intercalation compound (Li-GIC), which can introduce disorder into the originally ordered structure [96]. As the degree of intercalation increases, diffusivity becomes smaller [97]. For this reason, diffusivity is reported as a function of intercalation or electrode voltage [96-99]. Note that low quality carbon, which has low crystallinity, does not exhibit this staging phenomenon. The properties of carbonaceous materials depend largely on the starting materials (carbon precursor), and heat treatment of the final mixture.

During discharge, $\mathrm{Li}^{+}$ions are extracted from the layered graphite, passing through the electrolyte and intercalating between the $\mathrm{LiCoO}_{2}$ layers (Fig. 2.). 


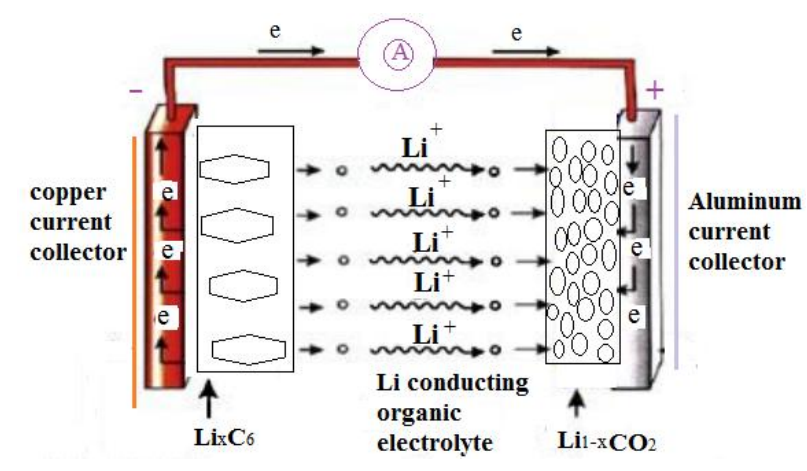

Fig. 2. A typical commercial lithium-ion battery

\section{DENSITY AND ENERGY OF LITHIUM IN DIFFUSION MODEL}

\subsection{Electron density profile models}

The electron density has been defined as [100-102]:

$$
\rho(r)=\eta_{i}\left|\varphi_{i}(r)\right|^{2}=\sum_{i} \eta_{i}\left|\sum_{l} C_{l, i} \chi_{i}(r)\right|^{2}
$$

where $\eta_{i}$ is the occupation number of orbital ( $\left.i\right), \varphi$ is the orbital wave function, $\chi$ is the basis function and $C$ is the coefficient matrix, the element of $i_{\text {th }}$ row $j_{\text {th }}$ column corresponds to the expansion coefficient of orbital $j$ with respect to basis function $i$. The atomic unit for electron density can be explicitly written as e/Bohr ${ }^{3}[100-102]$ :

$$
\begin{gathered}
\nabla \rho(r)=\left[\left(\frac{\partial \rho(r)}{\partial(x)}\right)^{2}+\left(\frac{\partial \rho(r)}{\partial(y)}\right)^{2}+\left(\frac{\partial \rho(r)}{\partial(z)}\right)^{2}\right]^{\frac{1}{2}} \\
\nabla^{2} \rho(r)=\frac{\partial^{2} \rho(r)}{\partial x^{2}}+\frac{\partial^{2} \rho(r)}{\partial y^{2}}+\frac{\partial^{2} \rho(r)}{\partial z^{2}}
\end{gathered}
$$

The positive and negative values of this function correspond to electron density being locally depleted and locally concentrated, respectively. The relationships between $\nabla^{2} \rho$ and the valence shell electron pair repulsion (VSEPR) model, chemical bond type, electron localization and chemical reactivity have been described by Bader [103].

\subsection{Hamiltonian kinetic energy density $K(r)$}

The kinetic energy density is not uniquely defined, since the expected value of kinetic energy operator $\left\langle\varphi\left|-\left(\frac{1}{2}\right) \nabla^{2}\right| \varphi\right\rangle(\mathbf{8})$ can be recovered by integrating kinetic energy density from alternative definitions. One of commonly used definition is:

$$
k(r)=-\frac{1}{2} \sum_{i} \eta_{i} \varphi_{i}^{*}(r) \nabla^{2} \varphi_{i}(r)
$$

Relative to $K(r)$, the local kinetic energy definition given below guarantees positives everywhere; hence the physical meaning is clearer and is more commonly used.

The Lagrangian kinetic energy density $G(r)$ is also known as positive definite kinetic energy density:

$$
\begin{gathered}
G(r)=\frac{1}{2} \sum_{i} \eta_{i} \mid \nabla\left(\left.\varphi_{i}\right|^{2}=\right. \\
=\frac{1}{2} \sum_{i} \eta_{i}\left\{\left[\left(\frac{\partial \varphi_{i}(r)}{\partial(x)}\right)^{2}+\left(\frac{\partial \varphi_{i}(r)}{\partial(y)}\right)^{2}+\left(\frac{\partial \varphi_{i}(r)}{\partial(z)}\right)^{2}\right]\right\}
\end{gathered}
$$

$K(r)$ and $G(r)$ are directly related by Laplacian of electron density

$$
\frac{1}{4} \nabla^{2} \rho(r)=G(r)-K(r)
$$

\subsection{Electron localization function (ELF)}

Becke and Edgecombe noted that spherically averaged like-spin conditional pair probability has direct correlation with the Fermi hole and suggested the electron localization function (ELF) [104]:

$$
\operatorname{ELF}(\mathrm{r})=\frac{1}{1+\left[D(r) / D_{0(r)}\right]^{2}}
$$

where

$$
D(r)=\frac{1}{2} \sum_{i} \eta_{i}\left|\nabla \varphi_{i}\right|^{2}-\frac{1}{8}\left[\frac{\left.|| \nabla \rho_{\alpha}\right|^{2}}{\rho_{\alpha}(r)}+\frac{\left.|| \nabla \rho_{\beta}\right|^{2}}{\beta(r)}\right]
$$

and

$$
D_{0(r)}=\frac{3}{10}\left(6 \pi^{2}\right)^{\frac{2}{3}}\left[\rho_{\alpha}(r)^{\frac{5}{3}}+\rho_{\beta}(r)^{\frac{5}{3}}\right]
$$

for a close-shell system, since

$$
\rho_{\alpha}(r)=\rho_{\beta}(r)=\frac{1}{2} \rho ;
$$

$D$ and $D_{0}$ terms can be simplified as $\mathrm{D}(\mathrm{r})$

$$
=\frac{1}{2} \sum_{i} \eta_{i}\left|\nabla \varphi_{i}\right|^{2}-\frac{1}{8}\left[\frac{|\nabla \rho|^{2}}{\rho(r)}\right]
$$

and

$$
D_{0(r)}=\frac{3}{10}\left(3 \pi^{2}\right)^{\frac{2}{3}} \rho(r)^{\frac{5}{3}}
$$

Savin et al. have reinterpreted ELF in terms of kinetic energy, [105] which makes ELF also meaningful for Kohn-Sham DFT wave-function or even post-HF wave-function. They indicated that $D(\mathbf{r})$ reveals the excess kinetic energy density caused by Pauli repulsion, while $D_{0}(r)$ can be con- 
sidered as Thomas-Fermi kinetic energy density [106].

Localized orbital locator (LOL) is another function for locating high-localization regions; likewise ELF, defined by Schmider and Becke in their papers $[106,107]$ :

$$
\operatorname{LOL}(r)=\frac{\tau(r)}{1+\tau(r)}
$$

where

$$
(r)=\frac{D_{0}(r)}{\frac{1}{2} \sum_{i} \eta_{i}\left|\nabla \varphi_{i}\right|^{2}}
$$

$D_{0}(r)$ for spin-polarized systems and closeshell systems are defined in the same way as in ELF [108].

\subsection{Local information entropy}

Local information entropy is a quantification of information; this theory was proposed by Shannon [109-111] in his study of information transmission in noise channels, and nowadays its application has been largely widened to other areas, including theoretical chemistry. For example, Aslangul and coworkers attempted to decompose diatomic and triatomic molecules into mutually exclusive space by minimizing information entropy [109].

Parr et al. discussed the relationship between information entropy and atom partition as well as molecular similarity [110]. Noorizadeh and Shakerzadeh suggested using information entropy to study aromaticity [111]. The formula of Shannon's information entropy for normalized and continuous probability function is:

$$
S=-\int P(x) \ln P(x) d x
$$

For chemical systems, if $P(\mathrm{x})$ is replaced by $\frac{\rho(r)}{N}$, then the integrand may be called the local information entropy of electrons:

$$
S(r)=-\frac{\rho(r)}{N} \ln \frac{\rho(r)}{N}
$$

where, $N$ is the total number of electrons in the current system.

\subsection{Electrostatic potential}

The total electrostatic potential (ESP) measures the electrostatic interaction between a unit point charges placed at $r$ and the system of interest. A positive (negative) value implies that current position is dominated by nuclear (electronic) charges. Molecular electrostatic potential (ESP) has long been widely used for prediction of nucleophilic and electrophilic sites.

It is also valuable in studying hydrogen bonds, halogen bonds, molecular recognitions and the intermolecular interaction of aromatics. Moreover, based on statistical analysis, Murray and coworkers found a set of functions called GIPF [112], which connect ESP to molecular surface and macroscopic properties. There have been many reviews published on ESP [113, 114]. The ESP evaluated under default value is accurate enough in general cases. Reduced density gradient (RDG) and $\operatorname{Sign}(\lambda 2)^{*} \rho$ are a pair of very important functions for revealing weak interaction regions [115]. The basic applications are exemplified in Sections 4.100.1 and 4.200.1. RDG is defined as:

$$
R D G(r)=\frac{1}{2\left(3 \pi^{2}\right)^{\frac{1}{3}}} \frac{|\nabla \rho(r)|}{\rho(r)^{\frac{4}{3}}} .
$$

By default $x$ is 0.05 , it can be nullified this treatment by setting the parameter to zero.

$$
\rho^{\text {pro }}(r)=\sum_{A} \rho_{A}^{\text {free,fit }}\left(r-R_{A}\right)
$$

where $\rho_{A}^{\text {free,fit }}$ is pre-fitted spherically averaged electron density of atom $A$ [100-102].

\section{COMPUTATIONAL DETAILS}

Calculations were performed using both Gaussian and GAMESS-US packages [116]. In this study, we have focused mainly on obtaining the optimized results for each tube from DFT methods including m06 and m06-L. The m062x, m06-L, and m06-HF are novel Meta hybrid DFT functions with a good correspondence in nonbonded calculations and are useful for calculating the energies of the distance between two h-BN sheets [117]. Pm6, extended-Hückel and Pm3MM including pseudo $=$ lanl 2 calculations using Gaussian program were performed for the non-bonded interaction between two sheets.

M06 and m06-L (DFT) functions are based on an iterative solution of the Kohn-Sham equation [118] of the density functional theory in a planewave set with projector-augmented wave pseudopotentials. The Perdew-Burke-Ernzerhof (PBE) [119] exchange-correlation (XC) function of the generalized gradient approximation (GGA) is adopted. The optimizations of the lattice constants 
and the atomic coordinates are made by the minimization of the total energy.

A fixed h-BN sheet geometry with $x \mathrm{Li}$ $(x=4,5,6,7)$ was chosen with no further geometry optimization. The outer ring, initially placed at the center of the inner tube, was rigidly axially shifted and rotated around the fixed inner shell. At each inter-tube configuration, a single-point calculation was carried out and the total energy recorded. The resulting sliding-rotation energy surfaces were used to fix our model in a better position.

We employed density functional theory with the van der Waals density function to model the exchange-correlation energies of h-BN sheets [120]. The double $\zeta$-basis set with polarization orbitals (DZP) were used for $\mathrm{x}$ Li over the h-BN sheets.

For non-covalent interactions, the B3LYP method is unable to describe van der Waals [121] capacitor systems by medium-range interactions such as the interactions of two cylinders. The B3LYP and most other functions are correctly insufficient to illustrate the exchange and correlation energy for distant non-bonded medium-range systems. Moreover, some recent studies have shown that inaccuracy in the medium-range exchange energies leads to large systematic errors in the prediction of molecular properties [122, 123].

We further calculated the interaction energy between $\mathrm{xLi}$ and $\mathrm{h}-\mathrm{BN}$ sheets. The interaction energy was calculated via an Mp6 method in all items, according to:

$$
\Delta E_{S}(e V)=\left\{E_{\text {total }}-\left(E_{\mathrm{xLi}}+E_{h-B N \text { sheets }}\right)\right\}+E_{B S S E}
$$

where $\Delta E_{S}$ is the stability energy of system.

The charge transfer and electrostatic potential-derived charge were also calculated using the Merz-Kollman-Singh [124], CHELP [125], or CHELPG [126] methods. The charge calculation methods based on molecular electrostatic potential (MESP) fitting are not well suited for treating larger systems, where some of the innermost atoms are located far away from the points at which the MESP is computed.

In such a condition, variations of the innermost atomic charges will not lead towards a significant change of the MESP outside the molecule, meaning that the accurate values for the innermost atomic charges are not well determined by MESP outside the molecule. This approach (CHELPG) is shown to be considerably less dependent upon molecular orientation than the original CHELP program. The results are comparable to those obtained by using CHELP.
In the CHELPG, atomic charges are fitted to reproduce the molecular electrostatic potential (MESP at a number of points around the molecule). The MESP is calculated at a number of grid points spaced $3.0 \mathrm{pm}$ apart and distributed regularly in a cube. Charges derived in this way do not necessarily reproduce the dipole moment of the molecule. CHELPG charges are frequently considered superior to Mulliken charges as they depend much less on the underlying theoretical method used to compute the wave function (and thus the MESP).

The representative atomic charges for molecules should be computed as average values over several molecular conformations.

The electron density (both gradient norm \& Laplacian) have been calculated, as have the value of the orbital wave-function, electron spin density, electrostatic potential from nuclear / atomic charges, electron localization function (ELF), localized orbital locator (LOL, defined by Becke \& Tsirelson [106]), total electrostatic potential (ESP), the exchange-correlation density, correlation hole and correlation factor, and average local ionization energy, using a Multifunctional Wave-function Analyzer [100-102].

The contour line map was drawn using Multiwfn software [100,101]. The solid lines indicate positive regions, dashed lines indicate negative regions. The contour line was drawn corresponding to Vander-wales (vdW) surface (electron density $=0.001$ a.u., defined by Bader [103]). This is useful to analyze distribution of electrostatic potential on the vdW surface.

The relief map was used to present the height value at every point. If values were too large they were truncated in the graph; a factor can be chosen to scale the data to avoid truncation. The graph is shown on the interactive interface. A shaded-surface map with and without projection are used in our representation of height values in each situation [100-102].

The methods in this work are based on our previous work [127-136]

\section{RESULT AND DISCUSSION}

We have listed the data of density, energy, electron localization function (ELF), localized orbital locator (LOL) and local entropy, gap energy, charge from ESP, electrostatic potential, ionization energy, the charges of two doped graphene electrodes and the stability energy of X-G-(h-BN)-X-G and dielectric in 5 tables (Tables 1-5) and these data are plotted in Figures 3-9. 

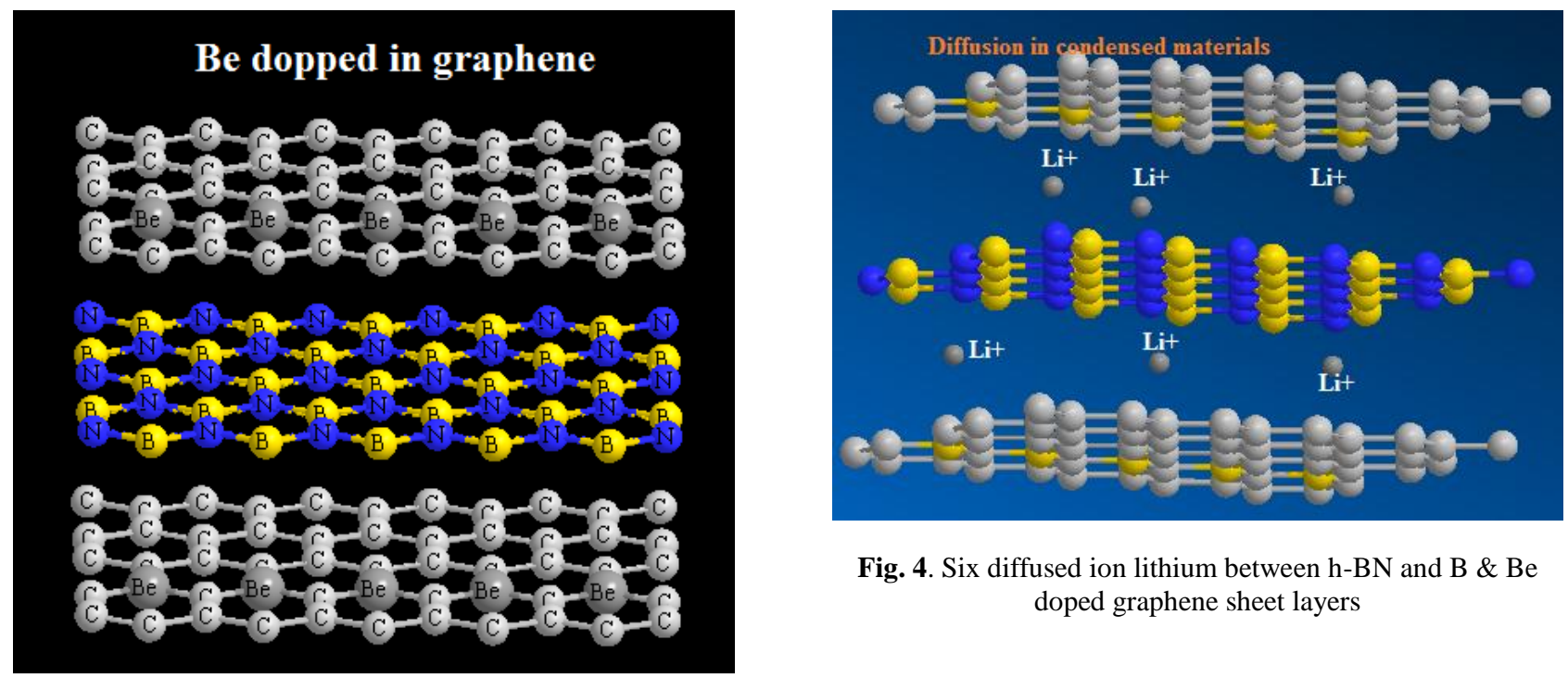

Fig. 4. Six diffused ion lithium between h-BN and B \& Be doped graphene sheet layers

Fig. 3. h-BN sandwich inside two boron graphene doped as two electrodes of B-G/h-BN/B-G and Be-G/h-BN/Be-G capacitors

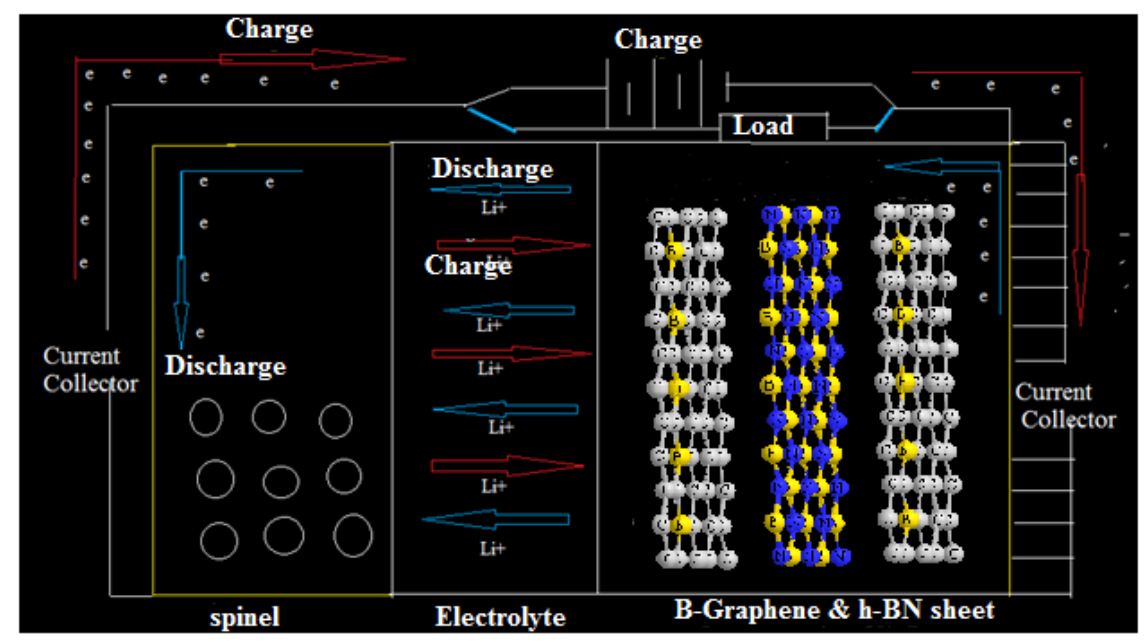

Fig. 5. Operating Li-ion battery

We have calculated the gradient norm and the Laplacian of electron density via equations 7 and 8 for the lithium diffused in the $X-G /(h-$ $\mathrm{BN}) / \mathrm{X}-\mathrm{G}$ system respectively and the data are listed in Table 1. For calculation of the electron spin density from the difference between alpha and beta density, we have used $\rho^{s}(r)=\rho^{\alpha}(r)-$ $\rho^{\beta}(r)$, then the spin polarization parameter function will be returned instead of spin density $\xi(r)=\frac{\rho^{\alpha}(r)-\rho^{\beta}(r)}{\rho^{\alpha}(r)+\rho^{\beta}(r)}$. The absolute value of $\xi$ going from zero to unity corresponds to the local region going from an un-polarized case to a completely polarized case, Table 1.

The kinetic energy density, Lagrangian kinetic energy density, and the electrostatic potential from nuclear/atomic charges can be calculated as equations 9 and 10 and: $V_{n u c}(r)=\sum_{A} \frac{Z_{A}}{\left|r-R_{A}\right|}$ where $R A$ and $Z A$ denote the position vector and nuclear charge of atom $A$, respectively, and are listed in Tables 1 and 2.

If pseudopotential is used, then $Z$ is the number of explicitly expressed electrons. $Z$ can stand for the atomic charges recorded in the file (the fourth column), at this time $V_{n u}$ is useful for analyzing the difference between exact electrostatic potential and the electrostatic potential reproduced by atomic charges. Note that at the nuclear position, this function will be infinite and may cause some numerical problems in the program; hence at these cases this function always returns 1000 instead of infinity. 
$\mathrm{T}$ a b l e 1

Density, energy, electron localization function $(E L F)$, localized orbital locator $(L O L)$ and local entropy for each Li of 6 lithium diffused on $X-G /(h-B N) / X-G(X=B, N$ and Be) mixed layers

\begin{tabular}{|c|c|c|c|c|c|c|c|c|c|c|c|}
\hline $\begin{array}{l}\text { Lithi- } \\
\text { um } \\
\text { No. }\end{array}$ & $\begin{array}{l}\text { Density } \\
\text { of all } \\
\text { electron } \\
\times\left(10^{-4}\right)\end{array}$ & $\begin{array}{l}\text { Density } \\
\text { of } a \\
\text { electron } \\
\times\left(10^{-4}\right)\end{array}$ & $\begin{array}{l}\text { Density of } \\
\beta \text { electron }\end{array}$ & $\begin{array}{l}\text { Spin } \\
\text { density } \\
\text { of elec- } \\
\text { tron }\end{array}$ & $\begin{array}{l}\text { Potential } \\
\text { energy } \\
\text { density } \\
\left(\times 10^{-3} \mathrm{~J}\right)\end{array}$ & $\begin{array}{l}\text { Hamilto- } \\
\text { nian } \\
\text { kinetic } \\
\text { energy } \\
\left(\times 10^{-4} \mathrm{~J}\right)\end{array}$ & $\times 10^{-3}$ & $\begin{array}{l}\text { Local } \\
\text { entropy }\end{array}$ & $\begin{array}{l}\text { Ellipti } \\
\text { city }\end{array}$ & $\times 10^{-7}$ & $\begin{array}{l}\text { Eta } \\
\text { index }\end{array}$ \\
\hline \multicolumn{12}{|c|}{$X=B$} \\
\hline $\mathrm{Li}+(1)$ & 0.24 & 0.12 & 0.12 & 0.0 & -0.24 & -0.11 & 0.15 & 0.41 & -0.30 & 0.30 & 0.14 \\
\hline $\mathrm{Li}+(2)$ & 0.30 & 0.15 & 0.15 & 0.0 & -0.23 & -0.15 & 0.16 & 0.50 & -0.15 & 0.31 & 0.16 \\
\hline $\mathrm{Li}+(3)$ & 0.28 & 0.14 & 0.14 & 0.0 & -0.28 & -0.12 & 0.19 & 0.53 & -0.20 & 0.34 & 0.16 \\
\hline $\mathrm{Li}+(4)$ & 0.26 & 0.13 & 0.13 & 0.0 & -0.29 & -0.15 & 0.18 & 0.52 & -0.30 & 0.32 & 0.14 \\
\hline $\mathrm{Li}+(5)$ & 0.32 & 0.16 & 0.16 & 0.0 & -0.22 & -0.14 & 0.19 & 0.47 & -0.31 & 0.35 & 0.15 \\
\hline $\mathrm{Li}+(6)$ & 0.38 & 0.19 & 0.19 & 0.0 & -0.27 & -0.12 & 0.17 & 0.53 & -0.22 & 0.31 & 0.17 \\
\hline \multicolumn{12}{|c|}{$\mathrm{X}=\mathrm{N}$} \\
\hline $\mathrm{Li}+(1)$ & 0.18 & 0.09 & 0.09 & 0.0 & -0.20 & -0.10 & 0.17 & 0.45 & -0.31 & 0.39 & 0.14 \\
\hline $\mathrm{Li}+(2)$ & 0.22 & 0.11 & 0.11 & 0.0 & -0.29 & -0.13 & 0.16 & 0.51 & -0.13 & 0.34 & 0.16 \\
\hline $\mathrm{Li}+(3)$ & 0.24 & 0.12 & 0.12 & 0.0 & -0.31 & -0.14 & 0.18 & 0.53 & -0.21 & 0.31 & 0.16 \\
\hline $\mathrm{Li}+(4)$ & 0.34 & 0.17 & 0.17 & 0.0 & -0.32 & -0.15 & 0.18 & 0.52 & -0.32 & 0.36 & 0.14 \\
\hline $\mathrm{Li}+(5)$ & 0.24 & 0.12 & 0.12 & 0.0 & -0.26 & -0.14 & 0.20 & 0.49 & -0.31 & 0.30 & 0.15 \\
\hline $\mathrm{Li}+(6)$ & 0.20 & 0.10 & 0.10 & 0.0 & -0.29 & -0.16 & 0.17 & 0.50 & -0.22 & 0.30 & 0.13 \\
\hline \multicolumn{12}{|c|}{$\mathrm{X}=\mathrm{Be}$} \\
\hline $\mathrm{Li}+(1)$ & 0.26 & 0.13 & 0.13 & 0.0 & -0.20 & -0.11 & 0.21 & 0.49 & -0.37 & 0.39 & 0.14 \\
\hline $\mathrm{Li}+(2)$ & 0.22 & 0.11 & 0.11 & 0.0 & -0.28 & -0.14 & 0.21 & 0.50 & -0.19 & 0.38 & 0.17 \\
\hline $\mathrm{Li}+(3)$ & 0.24 & 0.12 & 0.12 & 0.0 & -0.26 & -0.12 & 0.19 & 0.51 & -0.31 & 0.33 & 0.18 \\
\hline $\mathrm{Li}+(4)$ & 0.26 & 0.13 & 0.13 & 0.0 & -0.27 & -0.13 & 0.18 & 0.54 & -0.12 & 0.35 & 0.13 \\
\hline $\mathrm{Li}+(5)$ & 0.28 & 0.14 & 0.14 & 0.0 & -0.29 & -0.16 & 0.23 & 0.48 & -0.13 & 0.34 & 0.15 \\
\hline $\mathrm{Li}+(6)$ & 0.34 & 0.17 & 0.17 & 0.0 & -0.25 & -0.15 & 0.19 & 0.51 & -0.41 & 0.36 & 0.16 \\
\hline
\end{tabular}

The larger is the electron localization in a region, the more likely the electron motion is confined within it. If electrons are completely localized, then they can be distinguished from those outside. Bader found that the regions which have large electron localization must have large magnitudes of Fermi hole integration. However, the Fermi hole is a six-dimension function and thus difficult to visualize.

Since $D_{0}(r)$ from Eqs 11-13 is introduced into ELF as reference, what the ELF reveals is actually a relative localization. ELF is within the range of $[0,1]$. A large ELF value means that electrons are greatly localized, indicating that there is a covalent bond, a lone pair or inner shells of the atom involved. ELF has been widely used for a wide variety of systems, such as organic and inorganic small molecules, atomic crystals, coordination compounds, clusters, and for different problems, such as revealing the atomic shell structure, the classification of chemical bonding, verification of charge-shift bonds, and studying aromaticity.

When the actual kinetic energy term in $D(\mathbf{r})$ from equations 15 and 16 are replaced by Kirzhnits-type second-order gradient expansion, that is $\frac{1}{2} \sum_{i} \eta_{i}\left|\nabla \varphi_{i}\right|^{2} \approx D_{0}(r)+\frac{1}{72} \frac{|\nabla \rho|^{2}}{\rho(r)+\frac{1}{6} \nabla^{2} \rho(r)}$, so that ELF is totally independent from wavefunction, this can be used to analyze electron density from X-ray diffraction data. Of course Tsirelson's ELF can also be used to analyze electron density from quantum chemistry calculations, but it is not as good as the ELF defined by Becke [104] owing to the approximation introduced in the kinetic energy term; however, qualitative conclusions can still be recovered in general.

LOL has similar expression compared to ELF. Actually, the chemically significant regions that are highlighted by LOL and ELF are generally qualitatively comparable, while Jacobsen [108] pointed out that LOL conveys more decisive and clearer picture than ELF. Obviously LOL can be interpreted in kinetic energy way in the same way as for ELF; however LOL can also be interpreted in view of localized orbital. Small (large) LOL values usually appear in the boundary (inner) region of localized orbitals because the gradient of the orbital wave-function is large (small) in this area. The value range of LOL is identical to ELF, namely $[0,1]$.

In this work we have calculated the local information entropy for each lithium atom via Eqs. 19 and 20 and the integration of this function over whole space yields the information entropy. The data of local information entropy are listed in Table 1. 
Table 2

Gap energy, charge from ESP, electrostatic potential and Ionization energy for each Li of 6 lithium diffused on $X-G /(h-B N) / X-G(X=B, N$ and Be $)$ mixed layers

\begin{tabular}{ccccccc}
\hline \hline $\begin{array}{c}\text { Lithium } \\
\text { No. }\end{array}$ & $\begin{array}{c}\text { Gap } \\
(\mathrm{Kj} / \mathrm{mol})\end{array}$ & $\begin{array}{c}\text { Charge } \\
\text { from ESP } \\
\text { a.u. }\end{array}$ & $\begin{array}{c}\text { Electrostatic } \\
\text { properties } \\
\text { a.u. }\end{array}$ & $\begin{array}{c}\text { Average } \\
\text { local } \\
\text { ionization } \\
\text { energy }\end{array}$ & $\begin{array}{c}\text { Hole } \\
\text { for } a\end{array}$ & $\begin{array}{c}\text { Laplacian } \\
\text { of electron } \\
\text { density } \\
\times 10^{-3}\end{array}$ \\
\hline $\mathrm{Li+(1)}$ & 0.048 & 0.99 & -0.16 & 0.75 & -0.10 & 0.92 \\
$\mathrm{Li}+(2)$ & 0.027 & 0.94 & -0.09 & 0.80 & -0.40 & 0.19 \\
$\mathrm{Li}+(3)$ & 0.039 & 0.98 & -0.11 & 0.81 & -0.28 & 0.22 \\
$\mathrm{Li}+(4)$ & 0.040 & 0.96 & -0.12 & 0.82 & -0.15 & 0.31 \\
$\mathrm{Li}+(5)$ & 0.031 & 0.95 & 0.14 & 0.75 & -0.45 & 0.87 \\
$\mathrm{Li}+(6)$ & 0.065 & 0.93 & 0.08 & 0.78 & -0.50 & 0.92 \\
\hline & & & $\mathrm{X}=\mathrm{N}$ & & & \\
\hline $\mathrm{Li}+(1)$ & 0.048 & 0.98 & -0.12 & 0.75 & -0.31 & 0.86 \\
$\mathrm{Li}+(2)$ & 0.026 & 0.96 & -0.09 & 0.82 & -0.41 & 0.91 \\
$\mathrm{Li}+(3)$ & 0.035 & 0.93 & -0.15 & 0.83 & -0.39 & 0.92 \\
$\mathrm{Li}+(4)$ & 0.043 & 0.97 & -0.11 & 0.80 & -0.15 & 0.51 \\
$\mathrm{Li}+(5)$ & 0.038 & 0.91 & 0.12 & 0.75 & -0.45 & 0.67 \\
$\mathrm{Li}+(6)$ & 0.069 & 0.94 & 0.09 & 0.75 & -0.45 & 0.22 \\
\hline & & $\mathrm{X}=\mathrm{Be}$ & & & \\
\hline $\mathrm{Li}+(1)$ & 0.059 & 0.95 & -0.16 & 0.75 & -0.10 & 0.93 \\
$\mathrm{Li}+(2)$ & 0.037 & 0.93 & -0.08 & 0.82 & -0.40 & 0.11 \\
$\mathrm{Li}+(3)$ & 0.020 & 0.94 & -0.13 & 0.83 & -0.28 & 0.15 \\
$\mathrm{Li}+(4)$ & 0.039 & 0.93 & -0.12 & 0.84 & -0.15 & 0.11 \\
$\mathrm{Li}+(5)$ & 0.043 & 0.97 & 0.12 & 0.75 & -0.54 & 0.93 \\
$\mathrm{Li}+(6)$ & 0.051 & 0.99 & 0.09 & 0.76 & -0.54 & 0.22 \\
\hline \hline & & & & & \\
\hline
\end{tabular}

T a ble 3

The charges of two doped graphene electrodes and the stability energy of $x-G /(h-B N) / x-G$ $X=6$ atoms of $B e, B$ and $N$

\begin{tabular}{|c|c|c|c|c|c|}
\hline $\mathrm{Li}_{\mathrm{x}} \mathrm{G}-(\mathrm{h}-\mathrm{BN})-\mathrm{G}$ & $\begin{array}{l}\frac{1}{2} \text { Dielectric } \\
\text { thickness }(\AA)\end{array}$ & $\Delta E_{S}(e V)=$ & $q_{m-G}^{+}$ & $q_{\bar{m}-G}^{-}$ & $q_{(h-B N) 2}$ \\
\hline \multicolumn{6}{|c|}{$\mathrm{X}=\mathrm{B}$} \\
\hline Li G-(h-BN)-G & 3.99 & -12.14 & +0.25 & -0.20 & -0.05 \\
\hline $\mathrm{Li}_{2} \mathrm{G}-(\mathrm{h}-\mathrm{BN})-\mathrm{G}$ & 3.98 & -14.55 & +0.19 & -0.15 & -0.04 \\
\hline $\mathrm{Li}_{3} \mathrm{G}-(\mathrm{h}-\mathrm{BN})_{2}-\mathrm{G}$ & 4.01 & -21.84 & +0.013 & -0.012 & -0.001 \\
\hline $\mathrm{Li}_{4} \mathrm{G}-(\mathrm{h}-\mathrm{BN})_{2}-\mathrm{G}$ & 4.02 & -30.32 & +0.007 & -0.004 & -0.003 \\
\hline $\mathrm{Li}_{5} \mathrm{G}-(\mathrm{h}-\mathrm{BN})_{2}-\mathrm{G}$ & 3.96 & -43.07 & +0.22 & -0.12 & -0.10 \\
\hline $\mathrm{Li}_{6} \mathrm{G}-(\mathrm{h}-\mathrm{BN})_{2}-\mathrm{G}$ & 3.99 & -49.29 & +0.14 & -0.10 & -0.02 \\
\hline \multicolumn{6}{|c|}{$\mathrm{X}=\mathrm{N}$} \\
\hline Li G-(h-BN) $)_{2}-\mathrm{G}$ & 3.98 & -12.34 & +0.25 & -0.10 & -0.15 \\
\hline $\mathrm{Li}_{2} \mathrm{G}-(\mathrm{h}-\mathrm{BN})_{2}-\mathrm{G}$ & 3.97 & -14.15 & +0.14 & -0.11 & -0.03 \\
\hline $\mathrm{Li}_{3} \mathrm{G}-(\mathrm{h}-\mathrm{BN})_{2}-\mathrm{G}$ & 3.99 & -21.54 & +0.020 & -0.015 & -0.005 \\
\hline $\mathrm{Li}_{4} \mathrm{G}-(\mathrm{h}-\mathrm{BN})_{2}-\mathrm{G}$ & 4.01 & -30.34 & +0.008 & -0.004 & -0.004 \\
\hline $\mathrm{Li}_{5} \mathrm{G}-(\mathrm{h}-\mathrm{BN})_{2}-\mathrm{G}$ & 4.02 & -39.02 & +0.20 & -0.10 & -0.10 \\
\hline $\mathrm{Li}_{6} \mathrm{G}-(\mathrm{h}-\mathrm{BN})_{2}-\mathrm{G}$ & 4.00 & -41.45 & +0.15 & -0.020 & -0.13 \\
\hline \multicolumn{6}{|c|}{$\mathrm{X}=\mathrm{Be}$} \\
\hline Li G-(h-BN) $)_{2}-\mathrm{G}$ & 3.97 & -12.14 & +0.14 & -0.10 & -0.04 \\
\hline $\mathrm{Li}_{2} \mathrm{G}-(\mathrm{h}-\mathrm{BN})_{2}-\mathrm{G}$ & 3.97 & -14.85 & +0.18 & -0.14 & -0.04 \\
\hline $\mathrm{Li}_{3} \mathrm{G}-(\mathrm{h}-\mathrm{BN})_{2}-\mathrm{G}$ & 3.95 & -21.24 & +0.020 & -0.014 & -0.006 \\
\hline $\mathrm{Li}_{4} \mathrm{G}-(\mathrm{h}-\mathrm{BN})_{2}-\mathrm{G}$ & 3.99 & -32.32 & +0.008 & -0.004 & -0.004 \\
\hline $\mathrm{Li}_{5} \mathrm{G}-(\mathrm{h}-\mathrm{BN})_{2}-\mathrm{G}$ & 4.02 & -39.02 & +0.21 & -0.10 & -0.11 \\
\hline $\mathrm{Li}_{6} \mathrm{G}-(\mathrm{h}-\mathrm{BN})_{2}-\mathrm{G}$ & 4.03 & -33.49 & +0.13 & -0.010 & -0.120 \\
\hline
\end{tabular}


Ta ble 4

The dielectric of $X-G /(h-B N) / X-G$ modeled in various lithium number

\begin{tabular}{lccc}
\hline \hline & $\begin{array}{c}\frac{1}{2} \text { Dielectric } \\
\text { thickness }(\AA)\end{array}$ & $\begin{array}{c}\Delta\left(\boldsymbol{V}_{\boldsymbol{B}-\boldsymbol{G}}^{(\mathbf{1})}-\boldsymbol{V}_{\boldsymbol{B}-\boldsymbol{G}}^{(\mathbf{2})}\right. \\
\text { (a.u. })\end{array}$ & $k$ \\
\hline $\mathrm{Li} \mathrm{B-G/(h-BN)/B-G}$ & 3.99 & 2.2 & 1.83 \\
$\mathrm{Li}_{2} \mathrm{~B}-\mathrm{G} /(\mathrm{h}-\mathrm{BN}) / \mathrm{B}-\mathrm{G}$ & 3.98 & 2.5 & 1.43 \\
$\mathrm{Li}_{3} \mathrm{~B}-\mathrm{G} /(\mathrm{h}-\mathrm{BN}) / \mathrm{B}-\mathrm{G}$ & 4.01 & 3.3 & 2.05 \\
$\mathrm{Li}_{3} \mathrm{~N}-\mathrm{G} /(\mathrm{h}-\mathrm{BN}) / \mathrm{N}-\mathrm{G}$ & 3.99 & 2.8 & 2.07 \\
$\mathrm{Li}_{3} \mathrm{Be}-\mathrm{G} /(\mathrm{h}-\mathrm{BN}) / \mathrm{Be}-\mathrm{G}$ & 3.95 & 3.2 & 1.28 \\
$\mathrm{Li}_{2} \mathrm{~N}-\mathrm{G} /(\mathrm{h}-\mathrm{BN}) / \mathrm{N}-\mathrm{G}$ & 3.97 & 3.6 & 1.89 \\
$\mathrm{Li}_{2} \mathrm{G}-(\mathrm{h}-\mathrm{BN})_{2}-\mathrm{G}$ & 4.01 & 2.2 & 1.83 \\
\hline \hline
\end{tabular}

Weak interaction (equations 20 and 21) has significant influence on the conformation of macromolecules; however reproduction of electron density by $a b$ initio and grid data calculation of reduced density gradient (RDG) for such huge systems is always too time-consuming.

As lithium has an unpaired electron, leading to a difference in spin-up and spin-down, when two lithium atoms are adsorbed simultaneously electrons get paired and the magnetic moment disappears. As a result, spin polarized cluster has a gap, the size of which depends on adsorbed electron spin polarization.

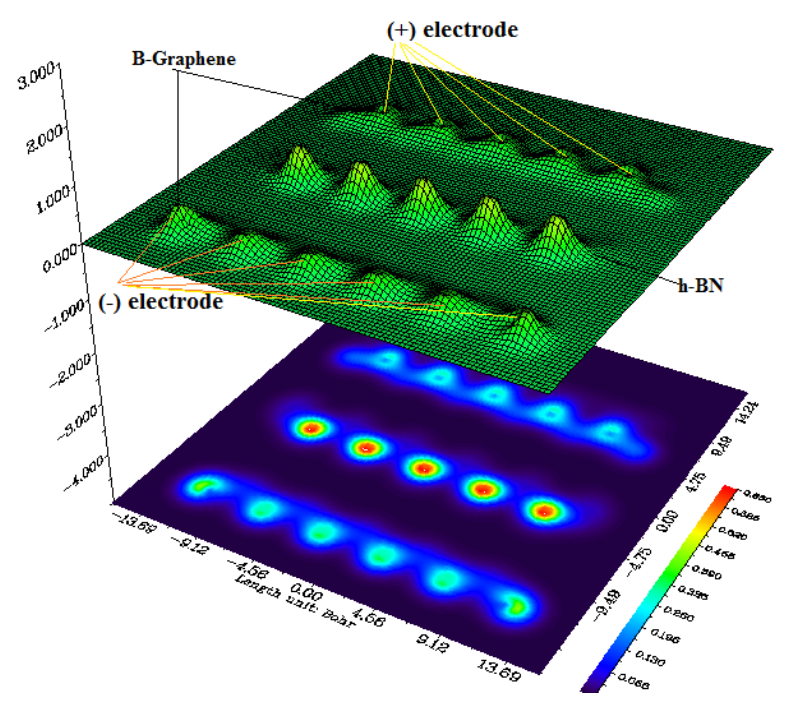

Fig. 6. Density with projection of B-G/ h-BN/B-G system

When used as electrode material, $\mathrm{X}-\mathrm{G} / \mathrm{h}$ $\mathrm{BN}) / \mathrm{X}-\mathrm{G}$ can effectively reduce the size of the active material, prevent agglomeration of nanoparti- cles, improve electron and ion transmission capacity, as well as enhancing the electrode's mechanical stability. As a result, electrode materials containing $\mathrm{X}-\mathrm{G} /(\mathrm{h}-\mathrm{BN}) / \mathrm{X}-\mathrm{G}$ have high capacity and good rate performance.
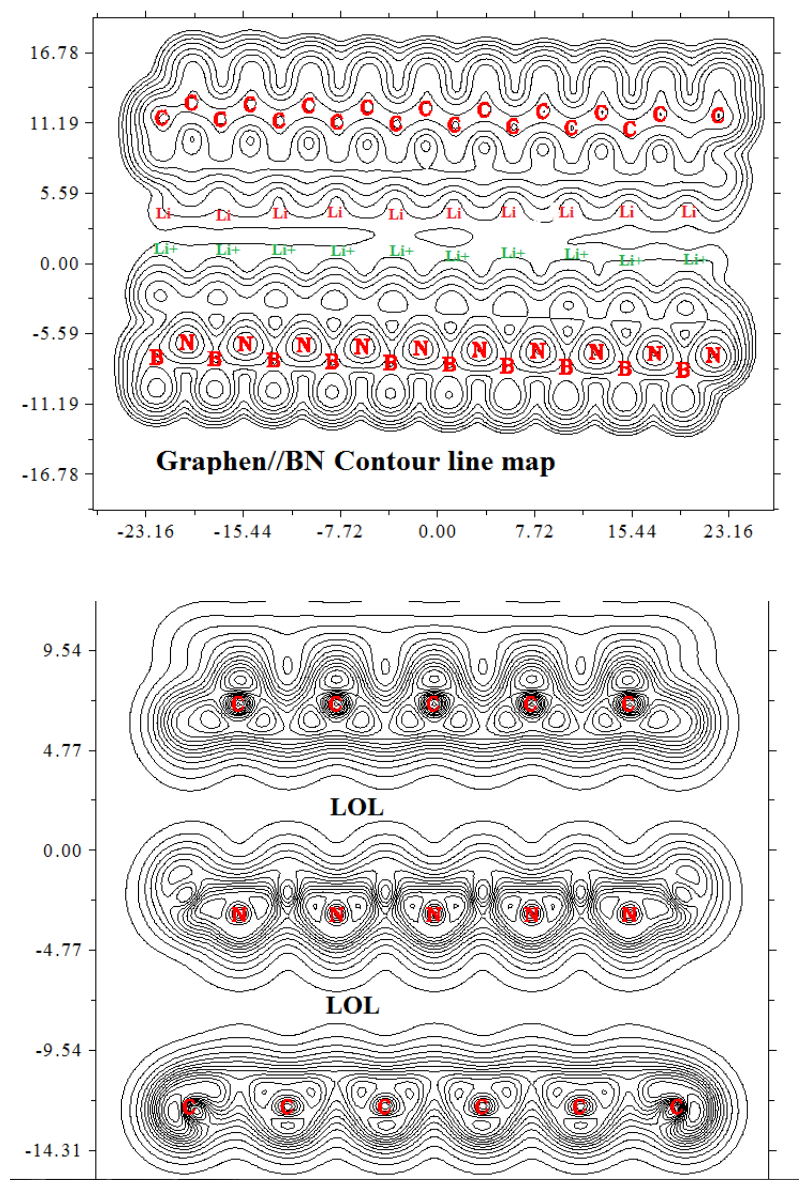

Fig. 7. LOL contour map for the interaction between $\mathrm{Li}+/ \mathrm{Li}$ in the $\mathrm{G} / / \mathrm{h}-\mathrm{BN} / / \mathrm{G}$ capacitor 
Table 5

Gap energy, charge from ESP, electrostatic potential and ionization energy for each Li of 10 lithium diffused on BN and graphene mixed layers

\begin{tabular}{cccccc}
\hline \hline $\begin{array}{c}\text { Lithium } \\
\text { No. }\end{array}$ & $\begin{array}{c}\text { ESP from } \\
\text { nuclear charge } \\
\text { a.u. }\end{array}$ & $\begin{array}{c}\text { ESP from } \\
\text { electrons } \\
\text { a.u. }\end{array}$ & $\begin{array}{c}\text { Total ESP } \\
\text { a.u. }\end{array}$ & $\begin{array}{c}\text { Average } \\
\text { local ionization } \\
\text { energy }\end{array}$ & $\begin{array}{c}\text { Hole } \\
\text { for } a \\
\times 10^{-8}\end{array}$ \\
\hline $\mathrm{Li}+(1)$ & 0.10 & -0.85 & 0.91 & 0.63 & -0.21 \\
$\mathrm{Li}+(2)$ & 0.10 & -0.96 & 0.90 & 0.61 & -0.15 \\
$\mathrm{Li}+(3)$ & 0.10 & -0.63 & 0.93 & 0.59 & -0.10 \\
$\mathrm{Li}+(4)$ & 0.10 & -0.74 & 0.92 & 0.58 & -0.34 \\
$\mathrm{Li}+(5)$ & 0.10 & -0.99 & 0.90 & 0.66 & -0.13 \\
$\mathrm{Li}+(6)$ & 0.10 & -0.10 & 0.89 & 0.59 & -0.18 \\
$\mathrm{Li}+(7)$ & 0.10 & -0.70 & 0.92 & 0.64 & -0.62 \\
$\mathrm{Li}+(8)$ & 0.10 & -0.10 & 0.89 & 0.56 & -0.11 \\
$\mathrm{Li}+(9)$ & 0.10 & -0.10 & 0.89 & 0.57 & -0.21 \\
$\mathrm{Li}+(10)$ & 0.10 & -0.10 & 0.89 & 0.60 & -0.29 \\
\hline \hline
\end{tabular}

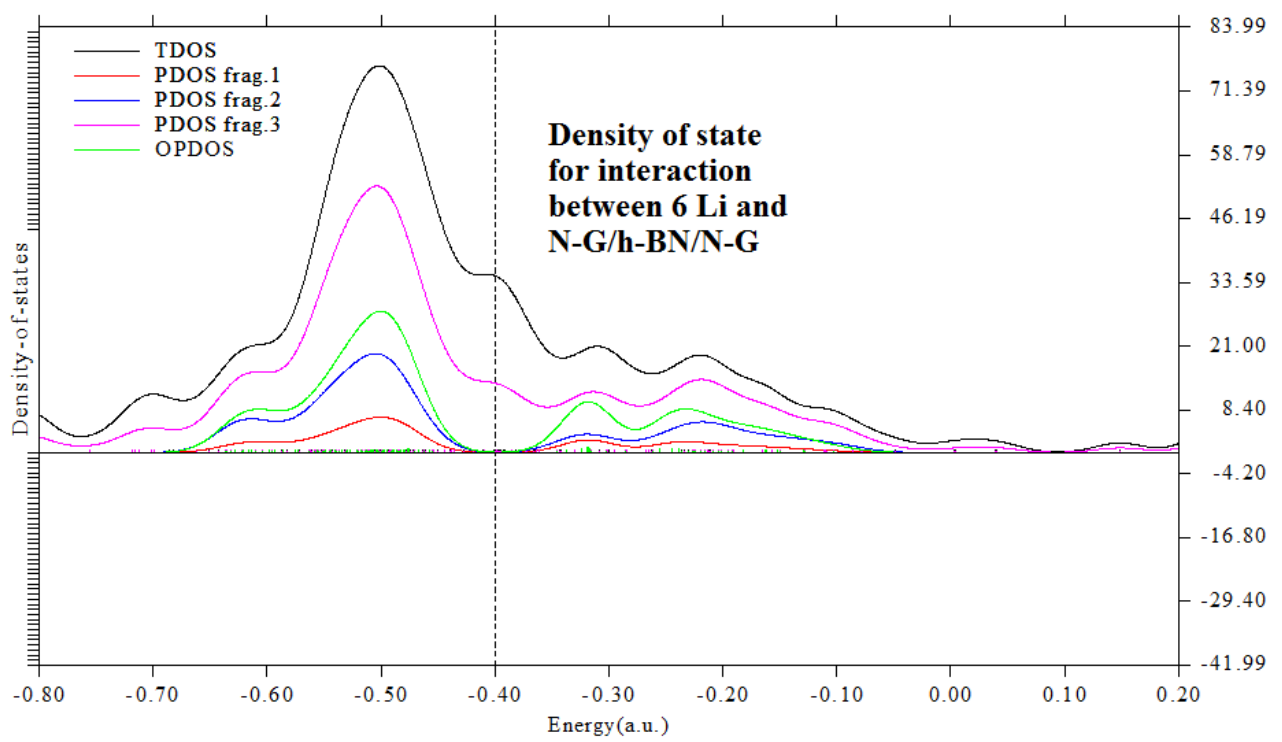

Fig. 8. Density of state plot of " 6 " lithium has been calculated inside nitrogen doped in graphene and h-BN sheets

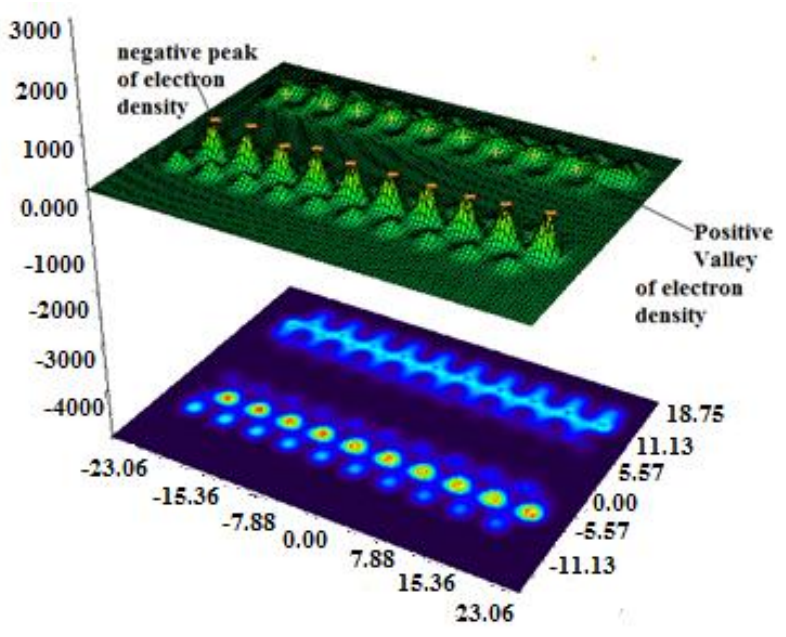

Fig. 9. 3D curves of negative and positive peak and hole from electron densities
The flexibility of $\mathrm{X}-\mathrm{G} /(\mathrm{h}-\mathrm{BN}) / \mathrm{X}-\mathrm{G}$ makes it an ideal material to buffer a metal electrode's volume expansion and contraction during the chargedischarge process. Further, the excellent electrical properties of $\mathrm{X}-\mathrm{G} /(\mathrm{h}-\mathrm{BN}) / \mathrm{X}-\mathrm{G}$ can enhance the conductivity of metallic electrode material. Smaller particles means the diffusion distance of lithium ions and electrons is reduced; this improves the material's rate performance. Finally, the lithium storage capacity for most metal oxide composite materials with $\mathrm{X}-\mathrm{G} /(\mathrm{h}-\mathrm{BN}) / \mathrm{X}-\mathrm{G}$ can be greatly useful.

\section{CONCLUSIONS}

In conclusion, we have performed our calculations to study the Li adsorption on graphene and boron nitride doped graphene with one layers of h-BN. Our results show that adsorption in h-BN//graphene is much stronger than pristine graphene. 
In this work we have shown the complex of $\mathrm{X}-\mathrm{G} /(\mathrm{h}-\mathrm{BN}) / \mathrm{X}-\mathrm{G}$ does demonstrate high electrical conductivity, good mechanical strength, excellent flexibility, great chemical stability and high specific surface area. This is especially noticeable when graphene is chemically converted with a greater proportion of functional groups, proving that it is suited for use as a base composite electrode material.

Additionally, we have found the structure of $\mathrm{X}-\mathrm{G} / \mathrm{h}-\mathrm{BN} / \mathrm{X}-\mathrm{G}$ can improve the capacity and electrical transport in C-BN sheets-based LIBs. Therefore, the modification of $\mathrm{BN}$ sheets and the design of $\mathrm{X}-\mathrm{G} / \mathrm{h}-\mathrm{BN} / \mathrm{X}-\mathrm{G}$ structure provide strategies for improving the performance of graphene including Boron and Nitrogen doped for based anodes. With the increase in defect density of h-BN sheets, the maximum capacity obtained is much higher than that of graphite. This study will help create better anode materials which can replace graphite for higher capacity and better cycling performance for LIBs.

\section{REFERENCES}

[1] R. C. Tatar and S. Rabii, Electronic properties of graphite: A unified theoretical study, Physical Review B, 25, 412641 (1982). https://doi.org/10.1103/PhysRevB.25.4126

[2] E. K. Sichel, R. E. Miller, M. S. Abrahams, C. J. Buiocchi, Superior thermal conductivity in suspended bilayer hexagonal boron nitride, Physical Review B, 13, 4607-11 (1976). DOI: 10.1038/srep25334

[3] S. G. Louie, M. L. Cohen, Electronic structure of a metalsemiconductor interface, Phys. Rev. B 13, 2461 (1976) https://doi.org/10.1103/PhysRevB.13.2461

[4] A. Zunger, A. Katzir, A. Halperin, Optical properties of hexagonal boron nitride, Physical Review B, 13, 5560 5573 (1976), DOI: 10.1103/PhysRevB.13.5560

[5] W. H. Balmain, Bemerkungen über die Bildung von Verbindungen des Bors und Siliciums mit Stickstoff und Gewissen J. Prakt. Chem, 27, 422-430 (1842).

[6] T. Sato, Report of National Institute for Research in Inorganic Materials, Tsukuba, Japan, 1987.

[7] Z. G. Yang, J. L. Zhang, M. C.W. Kintner-Meyer, X. C. Lu, D. W. Choi, J. P. Lemmon, J. Liu, Electrochemical energy storage for green grid, Chem. Rev, 111, 35773613 (2011). DOI: 0.1021/cr100290v

[8] D. Guerard, A. Herold, Intercalation of lithium into graphite and other carbons, Carbon, 13, 337-345 (1975). https://doi.org/10.1016/0008-6223(75)90040-8

[9] E. J. Yoo, J. Kim, E. Hosono, H. S. Zhou, T. Kudo, Large reversible Li storage of graphene nanosheet families for use in rechargeable lithium ion batteries, Nano Lett, 8 , 2277-2282 (2008). DOI: 10.1021/nl800957b

[10] G. Wang, X. P. Shen, J. Yao, and J. Park, Graphene nanosheets for enhanced lithium storage in lithium ion batteries, Carbon, 47, 2049-2053 (2009).
[11] T. Bhardwaj, A. Antic, B. Pavan, V. Barone, and B. D. Fahiman, Enhanced electrochemical lithium storage by graphene nanoribbons, JACS, 132, 12556-12558 (2010).

[12] T. Suzuki, T. Hasegawa, S. R. Mukai and H. Tamon, A theoretical study on storage states of Li ions in carbon anodes of Li ion batteries using, Carbon, 41, 1933-1939 (2003).

[13] T. Hasegawa, T. Suzuki, S. R. Mukai and H. Tamon, Semi-empirical molecular orbital calculations on the $\mathrm{Li}$ ion storage states in heteroatom-substituted carbon materials, Carbon, 42, 2195-2200 (2004). DOI: 10.1016/j.carbon.2004.04.045

[14] M. Noel and V. Suryanarayanan, Role of carbon host lattices in $\mathrm{Li}$-ion intercalation/de-intercalation processes, Journal of Power Sources, 111, 193-209 (2002). https://doi.org/10.1016/S0378-753(02)00308-7

[15] J. L. Tirado, Inorganic materials for the negative electrode of lithium-ion batteries: state-of-the-art and future prospects, Materials Science and Engineering R, 40, 103136 (2003).

[16] L. J. Fu, H. Liu, C. Li, Y. P. Wu, E. Rahm, R. Holze, H.Q. Wu, Surface modifications of electrode materials for lithium ion batteries, Solid State Sciences, 8, 113-128 (2006).

[17] E. Frackowiak and F. Béguin, Electrochemical storage of energy in carbon nanotubes and nano structured carbons, Carbon, 40, 1775-1787 (2002).

[18] M. S. Whittingham, A. J. Jacobson (Eds.), Intercalation Chemistry, Academic Press, 1982.

[19] S. A. Safran, D. R. Hamann, Long-range elastic interactions and staging in graphite intercalation compounds, Physical Review Letters, 42, (21), 1410-1413 (1979).

[20] M. D. Levi, D. Aurbach, J. Maier, Electrochemically driven first-order phase transitions caused by elastic responses of ion-insertion electrodes under external kinetic control, Journal of Electroanalytical Chemistry, 624, 251-261 (2008).

[21] H. Zabel, S. A. Solin (Eds.), Graphite Intercalation Compound, I, Springer-Verlag, 1990.

[22] Y. P. Wu, E. Rahm, R. Holze, Carbon anode materials for lithium ion batteries, Journal of Power Sources, 114, 228-236 (2003). https://doi.org/10.1016/S0378-7753(02)00596-7

[23] J. K. Lee, K. W. An, J. B. Ju, B. W. Cho, W. I. Cho, D. Park, K. S. Yun, Electrochemical properties of PANbased carbon fibers as anodes for rechargeable lithium ion batteries, Carbon, 39, 1299-1305 (2001).

[24] C. De las Casas and W. Z. Li, The defect size and Li concentration set two distinct fracture modes: abrupt fracture, J. Power Sources, 208, 74-85 (2012).

[25] Z. H. Yang and H. Q. Wu, Electrochemical intercalation of lithium into raw carbon nanotubes Mater. Chem. Phys,. 71, 7-11 (2001).

[26] K. S. Novoselov, A. K. Geim, S. V. Morozov, D. Jiang, Y. Zhang, S. V. Dubonos, I. V. Grigorieva, A. A. Firsov, Electric field effect in atomically thin carbon films, Science, 306, 666-669 (2004). DOI: $10.1126 /$ science. 1102896 
[27] B. Partoens, and F. M. Peeters, From graphene to graphite: electronic structure around the K point. Physical Review B, 74, 075404-1-075404-11 (2006)

[28] H. Tachikawa, and A. Shimizu, Diffusion dynamics of the $\mathrm{Li}$ atom on amorphous carbon: A direct molecular orbital-molecular dynamics study, Journal of Physical Chemistry B, 110, 20445-20450 (2006). DOI: $10.1021 /$ jp0616031

[29] K. Naoi, N. Ogihara, Y. Igarashi, A. Kamakura, Y. Kusachi, K. Utsugi, Disordered carbon anode for lithium-ion battery: I. An interfacial reversible redox action and anomalous topology changes, Journal of the Electrochemical Society 152 (6), A1047-A1053 (2005). doi:10.1149/1.1896531

[30] H. Groult, B. Kaplan, S. Komaba, N. Kumagai, V. Gupta, T. Nakajima and B. Simon, Journal of the Electrochemical Society, 150 (2), G67-G75 (2003).

[31] M. Endo, Y. Nishimura, T. Takahashi, K. Takeuchi, M.S. Dresselhaus, Lithium storage behavior for various kinds of carbon anodes in $\mathrm{Li}$ ion secondary battery, Journal of Physics and Chemistry of Solids, 57 (6-8), 725-728 (1996).

[32] T. Ohzuku, R. J. Brodd, An overview of positiveelectrode materials for advanced lithium-ion batteries, Journal of Power Sources 174, 449-456 (2007).

[33] M. Monajjemi, J. E. Boggs, A new generation of BnNn rings as a supplement to boron nitride tubes and cages, $J$. Phys. Chem. A, 117, $1670-1684$ (2013). DOI: $10.1021 /$ jp312073q.

[34] M. Monajjemi, V. S. Lee, M. Khaleghian, B. Honarparvar and F. Mollaamin, Theoretical description of electromagnetic non-bonded interactions of radical, cationic, and anionic NH2BHNBHNH2 inside of the B18N18 nanoring, J. Phys. Chem. C. 11415315 (2010). DOI: $10.1021 /$ jp104274z.

[35] M. Monajjemi. Metal-doped graphene layers composed with boron nitride-graphene as an insulator: a nanocapacitor, Journal of Molecular Modeling, 20, 2507 (2014). DOI: 10.1007/s00894-014-2507-y.

[36] M. Monajjemi, Non-covalent attraction of B2N (-, 0) and repulsion of $\mathrm{B} 2 \mathrm{~N}(+)$ in the $\mathrm{BnNn}$ ring: a quantum rotatory due to an external field, Theor Chem Acc, 134, 77 (2015). DOI 10.1007/s00214-015-1668-9.

[37] M. Monajjemi, Quantum investigation of non-bonded interaction between the $\mathrm{B} 15 \mathrm{~N} 15$ ring and $\mathrm{BH} 2 \mathrm{NBH} 2$ (radical, cation, anion) systems: a nano molecularmotor, Struct. Chem, 23551 (2012).

DOI: $10.1007 / \mathrm{s} 11224-011-9895-8$

[38] M. Monajjemi, M. Jafari Azan and F. Mollaamin, Density functional theory study on B30N20 Nano-cage in structural properties and thermochemical outlook, Fullerenes, Nanotubes, and Carbon Nanostructures, 21(6), 503-515 (2013).

DOI: $10.1080 / 1536383 X .2011 .629762$

[39] M. Monajjemi, Non-bonded interaction between $\mathrm{BnNn}$ (stator) and $\mathrm{BN}(-, 0,+) \mathrm{B}$ (rotor) systems: A quantum rotation in IR region, Chemical Physics, 425, 29-45 (2013). DOI: 10.1016/ j. chemphys. 2013. 07.014.

[40] K. S. Novoselov, A. K. Geim, S. V. Morozov, D. Jiang, Y. Zhang, S. V. Dubonos, I. V. Grigorieva, A. A. Firsov,
Electric field effect in atomically thin carbon films, Science, 306, 666-669 (2004).

DOI: $10.1126 /$ science. 1102896

[41] B. Partoens, F. M. Peeters, From graphene to graphite: electronic structure around the k point, Physical Review $B$, 74, 075404-1-075404-11 (2006).

[42] M. Monajjemi, M. Hosseini, M. Molaamin Theoretical study of boron nitride nanotubes with armchair forms, Fullerenes Nanotubes and Carbon Nanostructures, 21, 5, 381-393 (2013). DOI: $10.1080 / 1536383 X .2011 .629752$

[43] L. Ravagnan, P. Piseri, M. Bruzzi, S. Miglio, G. Bongiorno, A. Baserga, C. S. Casari, A. Li Bassi, C. Lenardi, Y. Yamaguchi, T. Wakabayashi, C. E. Bottani and P. Milani, Carbon-based materials with unique physical and electronic properties, Physical Review Letters 98, 216103-1-216103-4 (2007). https://doi.org/10.1103/PhysRevLett.98.216103

[44] P. N. Vishwakarma, S. V. Subramanyam, Hopping conduction in boron doped amorphous carbon films, Journal of Applied Physics, 100, 113702-1-113702-5 (2006). https://doi.org/10.1063/1.2372585

[45] G. Rizzoni, Principles and Applications of Electrical Engineering, 4th ed., McGraw Hill, pp. 43-44, 2004

[46] K. Kitoh, and H. Nemoto, $100 \mathrm{Wh}$ large size batteries and safety tests, Journal of Power Sources, 81-82, 887890 (1999).

[47] H. Maleki, S. A. Hallaj, J. R. Selman, R. B. Dinwiddie, H. Wang, Thermal properties of lithium-ion battery and components, Journal of the Electrochemical Society, 146 (3), 947-954 (1999). DOI: 10.1149/1.1391704.

[48] J. M. Tarascon, M. Armand, Issues and challenges facing rechargeable lithium batteries, Nature, 414, 359 (2001). DOI:10.1038/35104644

[49] A. S. Claye, J. E. Fischer, C. B. Huffman, A. G. Rinzler, R. E. Smalley, Electrochemical doping of single-wall carbon nanotube (SWNT) films and concomitant changes in their, Journal of Electrochemical Society, 147, 2845 (2000). https://doi.org/JESOAN

[50] J. N. Barisci, G. C. Wallace, R. H. Baughman, carbon $(G C)$, graphite and diamond, mainly in the special, Electrochimica Acta, 46, 509 (2000).

[51] J. Zhao, A. Buldum, J. Han, J. P. Lu, First-principles study of Li intercalated nanotube rope, Physics Review Letters 85, 1706 (2000).

[52] G. T. Wu, et al., Lithium insertion into $\mathrm{CuO}$ carbon nanotubes, Journal of Power Sources, 75 175-179 (1998).

[53] H. Jalilian and M. Monajjemi, Capacitor simulation including of $\mathrm{X}$-doped graphene $(\mathrm{X}=\mathrm{Li}, \mathrm{Be}, \mathrm{B})$ as two electrodes and $(\mathrm{h}-\mathrm{BN}) \mathrm{m}(\mathrm{m}=1-4)$ as the insulator, Japanese Journal of Applied Physics, 54, 085101, (2015). DOI: 10.7567/JJAP.54.085101.

[54] S. Y. Chew, S. H. Ng, J. Wang, Flexible free-standing carbon nanotube films for model lithium-ion batteries, Carbon, 47, 2976-2983, (2009).

[55] M. Monajjemi, M. Khaleghian, EPR Study of Electronic Structure of [CoF6] 32 and $\mathrm{B}_{18} \mathrm{~N}_{18}$ Nano Ring Field Ef- 
fects on Octahedral Complex, Journal of Cluster Science. 22 (4), 673-692, (2011).

DOI: $10.1007 / \mathrm{s} 10876-011-0414-2$

[56] E. Frackowiak, S. Gautier, H. Gaucher, S. Bonnamy, F. Beguin, Electrochemical storage of lithium multi-walled carbon nanotubes, Carbon 37, 61-69, (1999).

[57] M. Monajjemi, M. Falahati, F. Mollaamin, Computational investigation on alcohol nano-sensors in combination with carbon nanotube: a Monte Carlo and ab initio simulation, Ionics, 19, 1, 155-164 (2013). DOI: $10.1007 / \mathrm{s} 11581-012-0708-\mathrm{x}$

[58] S. Y. Chew, S. H. Ng, J .Wang, P. Novak, F. Krumeich, S. L. Chou, J. Chen, H . K. Liu. Carbon, 47, 2976 (2009). https://doi.org/10.1016

[59] E. Frackowiak, S. Gautier, H. Gaucher, S. Bonnamy and F. Beguin, Electrochemical storage of lithium multiwalled carbon nanotubes, Carbon, 37, 61 (1999).

[60] J. Zhao, Q.Y. Gao, C. Gu, Y. Yang, Preparation of multi-walled carbon intercalation behavior of Li ions, Chemical Physics Letters, 358, 77-82 (2002).

[61] Y. J. Hu, J. A. Jin , P. Wu , H. Zhang, C. X. Cai , Graphene-gold toward the oxygen reduction and glucose oxidation, Electrochim. Acta. 56, 491 (2010).

[62] G. L. Che, B. B. Lakshmi, E. R. Fisher, C. R. Martin, Carbon nano-tubule for electrochemical energy storage and production, Nature, 393, 346 (1998). https://doi.org/10.1038/30694

[63] N. A. Kaskhedikar, J. Maier, Lithium storage in carbon nanostructures, Adv. Mater, 21, 2664-2680 (2009)

[64] A. Thess, A, R. Lee, P. Nikolaev, H. Dai, P. Petit, J. Robert, C. Xu, Y. H .Lee, S.G. Kim, A. G. Rinzler. Science, 273, 483-487 (1996)

[65] Y. Ando, X. Zhao, H. Shimoyama, G. Sakai and K. Kaneto, Physical properties of multiwalled carbon nanotubes, Int. J. Inorg. Mater, 1, 77-82 (1999). https://doi.org/10.1016/S1463-0176(99)00012-5

[66] M. F. Yu, O. Lourie, M. J. Dyer, K. Moloni, T. F. Kelly and R. S. Ruoff, Strength and breaking mechanism of multiwalled carbon nanotubes under tensile load, Science, 287, 637-640 (2000). https://doi.org/10.1126/science.287.5453.637

[67] L. F. Cui, L. Hu, J. W. Choi, and Y. Cui, Light-weight free-standing carbon nanotube-silicon films for anodes of lithium ion batteries, ACS Nano, 4, 3671-8 (2010). DOI: $10.1021 / \mathrm{nn} 100619 \mathrm{~m}$

[68] Q. Wang, J. H. Li, Facilitated lithium storage in MoS2, Journal of Physical Chemistry C, 111, 1675-1682 (2007).

[69] G. Maurin, Ch. Bousquet, F. Henn, P. Bernier, R. Almairac, B. Simon, Electrochemical intercalation of lithium into multiwall carbon nanotubes. Chem. Phys. Lett, 312, 14-18 (1999).

[70] A. Kiebele, G. Gruner, Carbon nanotube based battery architecture, Applied Physics Letters, 91, 144104 (2007). http://doi.org/10.1063/1.2795328

[71] J. Chen, Systematic electron crystallographic studies of self-assembled binary nanocrystal super-lattices, Chemical Materials, 19, 4183-4188, (2007).
[72] W. Wang, R. Epur, P. N. Kumta, Vertically aligned silicon/carbon nanotube (VASCNT) arrays: hierarchical anodes for lithium-ion battery, Electrochemical Communications, 13, 429-432 (2011).

[73] C. De las Casas, W. Z. Li, A review of application of carbon nanotubes for lithium ion battery anode material, J. Power Sources, 208, 74-85 (2012).

[74] Z. H .Yang and H. Q. Wu, Mater. Chem. Phys, 71, 7-11 (2001).

[75] D. Qian, G. J. Wagner, W. K. Liu, M. F. Yu, R. S. Ruoff, Mechanics of carbon nanotubes. Appl. Mech. Rev. 55, 495-533 (2002).

[76] A. Rubio, J. L. Corkill, M. L. Cohen, Theory of graphitic boron nitride nanotubes, Phys. Rev. B, 49, 5801 (1994).

[77] N. G. Chopra, R. J. Luyken, K. Cherrey, Boron nitride nanotubes, Science, 269, 966 (1995). https://doi.org/SCIEAS

[78] L. F. Sun, S. S. Xie, W. Liu, W. Y. Zhou, and Z. Q. Liu, Nature, 403, 384 (2000). DOI:10.1038/35000290

[79] S. Yang, H. Song, X. Chen, A. V. Okotrub, L. G. Bulusheva, Electrochemical performance of arcproduced carbon nanotubes as anode material for lithium-ion batteries. Electrochim. Acta, 52, 5286-5293, (2007)

[80] S. Okada, S. Saito, A. Oshiyama, Interwall interaction and electronic structure of double-walled BN nanotubes, Phys. Rev. B 65, 165410 (2002). https://doi.org/10.1103/PhysRevB.65.165410

[81] D. S. Wilkinson, Mass Transport in Solid and Fluids, Cambridge University Press, 2000.

[82] H. Mehrer, Diffusion in Solids - Fundamentals, Methods, Materials, 2007, pp. 27-36.

[83] D. A. Porter, K. E. Easterling, Phase Transformations in Metals and Alloys, $2^{\text {nd }}$ edition, Chapman \& Hall, 1992, pp. 1-109.

[84] R. H. Petrucci, W. S. Harwood, General Chemistry, $7^{\text {th }}$ edition, Prentice-Hall, 1997, pp. 315-343.

[85] H. Dehmelt, A single atomic particle forever floating at rest in free space: New Value for Electron Radius, Physica Scripta, T22, 102-110 (1988). http://dx.doi.org/10.1088/0031-8949/1988/ T22/016

[86] J. Molenda, Electronic aspect of intercalation in layered, spinel and olivine type cathode materials, Polish Journal of Chemistry, 78, 1413-1421 (2004).

[87] C. Wang and J. Hong, Ionic/electronic conducting characteristics of LiFePO4 cathode materials, Electrochemical and Solid-State Letters, 10 (3) A65-A69 (2007).

[88] R. A. Huggins, in: C. A. C. Sequeira, A. Hooper (Eds.), Proceedings of the NATO Advanced Study Institute on Solid State Batteries, Alcabideche, Portugal, September 2-17, 1984.

[89] N. A. Kaskhedikar, J. Maier, Lithium storage in carbon nanostructures, Advanced Materials, 21, (25-26), 26642680 (2009).

[90] J. Cabana, L. Monconduit, D. Larcher, M. R. Palacin, Beyond intercalation-based Li-ion batteries: the state of 
the art and challenges of electrode materials reacting through, Advanced Materials, 22, (35), E170-E192 (2010).

[91] P. Poizot, S. Laruelle, S. Grugeon, L. Dupont, L. J. M. Tarascon, Synthesis and enhanced negative-electrode materials for lithium-ion batteries, Nature, 407, (6803), 496-499 (2000).

[92] J. C. Park, J. Kim, H. Kwon, H. Song, Gram-scale synthesis of $\mathrm{Cu} 2 \mathrm{O}$ nano-cubes and subsequent oxidation to anode materials, Advanced Materials, 21, (7), (2009).

[93] C. M. Ban, Z. C. Wu, D. T. Gillespie, L. Chen, Y. F. Yan, J. L. Blackburn, A. C. Dillon, Materials, 22, (20) (2010).

[94] G. M. Ehrlich, in: David Linden (Ed.), Handbook of Batteries, 3rd ed., McGraw Hill, 35.16-35. 21 (2002).

[95] A. V. Churikov, N. A. Gridina, N. V. Churikova, in: V. Igor Barsukov, S. Christopher Johnson, E. Joseph, Doninger, Z. Vyacheslav Barsukov (Eds.), New Carbon Based Materials for Electrochemical Energy Storage Systems, Springer, 269-276 (2006).

[96] A. Funabiki, M. Inaba, Z. Ogumi, S.I. Yuasa, J. Otsuji and A. Tasaka, Journal of the Electrochemical Society 145 (1) 172-178 (1998).

[97] Y. N. Li and J. Yang, Z. Jiang, Intercalation of lithium ions into bulk and powder highly oriented pyrolytic graphite, Journal of Physics and Chemistry of Solids, 67 882-886 (2006).

[98] B. Scrosati and J. Garche, Lithium batteries: status, prospects and future, Journal of Power Sources, 195, (9), 2419-2430 (2010).

[99] F. Cheng, J. Liang, Z. Tao and J. Chen, Functional materials for rechargeable batteries, Advanced Materials, 23 , (15), 1695-1715 (2011).

[100] T. Lu, F. Chen Multiwfn: A Multifunctional wavefunction analyzer, Acta Chim. Sinica, 69, 2393$2406(2011)$

[101] T. Lu, F. Chen, The target molecular systems are the isomeric $\mathrm{CH}_{3} \mathrm{OBr} / \mathrm{BrCH}_{2} \mathrm{OH}$ system and Marching Tetrahedra algorithm, J. Mol. Graph. Model, 38, 314323 (2012)

[102] T. Lu, F. Chen Multiwfn: A Multifunctional wavefunction analyzer, J. Comp. Chem., 33, 580-592, (2012).

[103] R. F. W. Bader, atoms in Molecule: A quantum Theory, Oxford Univ. press, Oxford, (1990).

[104] Becke and Edgecombe, A simple measure of electron localization in atomic and molecular systems, J. Chem. Phys., 92, 5397-5403 (1990).

[105] A. Savin Angew, Atomic shell structure and electron numbers, Chem. Int. Ed.Engl., 31, 187 (1992). https://doi.org/10.1002/anie.199201871

[106] V. G. Tsirelson, Yu. A. Abramov. On the possibility of kinetic energy density evaluation from the function from electron density, Chem. Phys. Lett, 351, 142-148 (2002).

[107] H. L. Schmider, A. D. Becke, Extracting information about chemical bonding from molecular electron, $J \mathrm{Mol}$ Struct (Theochem) 527, 5150 (2000). https://doi.org/10.1016/S0166-1280(00)00477-2
[108] Jacobsen, Localized-orbital locator (LOL) profiles of chemical bonding, Can. J. Chem, 86 (7), 695-702, (2008). DOI: 10.1139/v08-052

[109] C. Aslangul, R. Constanciel, R. Daudel and P. Kottis, Aspects of the localizability theory and related methods, Adv. Quantum Chem 6, 93-141, (1972). https://doi.org/10.1016/S0065-3276 (08)60542-0

[110] R. G. Parr, P. W. Ayers, R. F. Nalewajski, What is an atom in a molecule?, J Phys Chem A, 109, 3957-3959 (2005).

[111] S. Noorizadeh, E. Shakerzadeh, Shannon entropy as a new measure of aromaticity, Shannon aromaticity, Phys. Chem. Chem. Phys, 12, 4742-4749 (2010). DOI: $10.1039 / \mathrm{b} 916509 \mathrm{f}$.

[112] J. S. Murray, P. Politzer, in: Quantitative Treatments of Solute/Solvent Interactions, J. Mol. Struct. (Theochem) 307, 55 (1994).

[113] J. S. Murray, The electrostatic potential: an overview, Comput. Mol. Sci., 1, 153 (2011).

[114] P. Politzer, J. S. Murray, Molecular electrostatic potentials and chemical reactivity in atoms and molecules, Theor. Chem. Acc., 108, 134-142 (2002).

[115] J. S. Murray, P. Lane, T Brinck, K. Paulsen, M.E. Grice P. Politzer, J. Phys. Chem, 97, 9396 (1993).

[116] M. W. Schmidt, K. K. Baldridge, J. A. Boatz, S. T. Elbert, M. S. Gordon, J. H. Jensen, S. Koseki, N. Matsunaga, K. A. Nguyen et al., A molecular system in FMO is divided into $N$ fragments, also referred to as monomers 14 (11), 1347-1363 (2004). https://doi.org/10.1002/jcc.540141112

[117] Yan Zhao, Donald G. Truhlar, Theor Chem Account, 120, 215-241 (2008).

[118] W. Kohn, L. J. Sham, Self-Consistent Equations Including Exchange and Correlation, Phys. Rev., 140 A, 11331138 (1965). DOI:10.1103/PhysRev.140.A1133

[119] J. P. Perdew, K. Burke Ernzerhof, Generalized gradient approximation made simple, Phys. Rev. Lett, 77, 38653868 (1996).

[120] D. L. Klein, R. Roth, A. K. L. Lim, A. P. Alivisatos and P. L. McEuen, Nature (London), 389, 699 (1997), https://doi.org/NATUAS.

[121] Yan Zhao, Donald G. Truhlar, Benchmark data for interactions in zeolite model complexes and their use, Accounts of Chemical Research, 41(2), 157-167 (2008).

[122] C. E. Check, T. M. Gilbert, Progressive Systematic Underestimation of Involving Polycarbon Hydrocarbons, $J$. Org. Chem 70, 9828-9834 (2005).

[123] S. Grimme, Seemingly, Simple stereoelectronic effects in alkane isomers and the implications for Kohn-Sham density functional, Angew. Chem., Int. Ed. 45, 4460 4464 (2006).

[124] B. H. Besler, K. M. Merz, P. A. Kollman, Electrostatics in biornolecular structure and dynamics, J. Comp. Chem. 11, 431 (1990). https://doi.org/10.1002/jcc.540110404

[125] L. E. Chirlian, M. M. Francl, Atomic charges derived from electrostatic potentials: a detailed study, J.comp.chem, 8, 894-905 (1987). https://doi.org/JCCHDD 
[126] G. M. Brneman, K. B. Wiberg, J. Comp Chem, 11, 361, J Clust Sci (22):673-692 (1990).

[127] F. Mollaamin, M. Monajjemi, Fractal dimension on carbon nanotube-polymer composite materials using percolation theory, Journal of Computational and Theoretical Nanoscience 9, 4, 597-601 (2012). DOI: $10.1166 /$ jctn.2012.2067

[128] M. Monajjemi, H. Chegini, F. Mollaamin, P. Farahani, Theoretical studies of solvent effect on normal mode analysis and thermodynamic properties of zigzag $(5,0)$ carbon nanotube, Fullerenes, Nanotubes, and Carbon Nanostructures, 19, 469-482, 2011. DOI: 10.1080/1536383X.2010.494783

[129] M. Monajjemi, R. Faham, F. Mollaamin, Ab initio study of direct diffusion pathway for $\mathrm{H}+, \mathrm{Li}+, \mathrm{Na}+\mathrm{K}+$ cations into the $(3,3),(4,4)$, and $(5,5)$ open-ended singlewalled carbon nanotubes, Fullerenes, Nanotubes and Carbon Nanostructures, 20, 163-169 (2012).

DOI: 10.1080/1536383X.2010.533310

[130] H. Yahyaei, M. Monajjemi, Theoretical study of different solvent and temperature effects on double-walled carbon nanotubes (DWNTs) and calixarene with amino acid: A QM/MM study, Fullerenes, Nanotubes, and Carbon Nanostructures, 22(4), 346-361 (2014). DOI: $10.1080 / 1536383 X .2012 .684190$

[131] V. S. Lee, P. Nimmanpipug, F. Mollaamin, et al., Investigation of single wall carbon nanotubes electrical prop- erties and normal mode analysis, Russian Journal of Physical Chemistry A, 83, 13 2288-2296 (2009). DOI: $10.1134 / \mathrm{S} 0036024409130184$

[132] M. Monajjemi, M. Falahati, F. Mollaamin, Computational investigation on alcohol nano-sensors in combination with carbon nanotube: a Monte Carlo and ab initio simulation, Ionics, 19, 155-164, (2013). DOI: $10.1007 / \mathrm{s} 11581-012-0708-\mathrm{x}$

[133] H. Yahyaei, M. Monajjemi, H. Aghaie, Monte Carlo quantum calculation for double-walled carbon nanotubes (DWNTs) combined to calixarene, Journal of Computational and Theoretical Nanoscience, 10, 2332-2341 (2013). DOI: 10.1166/jctn.2013.3210

[134] M. Monajjemi, Cell membrane causes the lipid bilayers to behave as variable capacitors: A resonance with selfinduction of helical proteins, Biophysical Chemistry. 207, 114 -127 (2015). DOI: 10.1016/j.bpc.2015.10.003

[135] L. Mahdavian, M. Monajjemi, Alcohol sensors based on SWNT as chemical sensors: Monte Carlo and Langevin dynamics simulation, Microelectronics Journal. 41(23), 142-149 (2010). DOI: 10.1016/j.mejo.2010.01.011

[136] M. Monajjemi, Liquid-phase exfoliation (LPE) of graphite towards graphene: An ab initio study, Journal of Molecular Liquids, 230, 461-472 (2017). DOI: 10.1016/j.mejo.2010.01.011 